Carolina Okamoto Vieira

Mecanismo hemostático da serpente Crotalus durissus terrificus (Ophidia: Viperidae, Crotalinae)

Hemostatic mechanism of Crotalus durissus terrificus snake (Ophidia: Viperidae, Crotalinae)

São Paulo

2014 
Carolina Okamoto Vieira

\section{Mecanismo hemostático da serpente Crotalus durissus terrificus (Ophidia: Viperidae, Crotalinae)}

Hemostatic mechanism of Crotalus durissus terrificus snake (Ophidia: Viperidae, Crotalinae)

Tese apresentada ao Instituto de Biociências da Universidade de São Paulo, para a obtenção de Título de Doutor em Ciências, na Área de Fisiologia.

Orientadora: Ida S. Sano Martins

Exemplar corrigido. O original encontra-se disponível para consulta no Instituto de Biociências da USP.

São Paulo 


\section{Ficha Catalográfica}

\section{Vieira, Carolina Okamoto}

Mecanismo hemostático da serpente Crotalus durissus terrificus (Ophidia:

Viperidae, Crotalinae)

90 páginas

Tese (Doutorado) - Instituto de Biociências da Universidade de São Paulo. Departamento de Fisiologia.

1. Hemostasia 2. Crotalus durissus terrificus 3. Coagulação I. Universidade de São Paulo. Instituto de Biociências. Departamento de Fisiologia.

\section{Comissão Julgadora:}


Autorizo a reprodução e divulgação total ou parcial deste trabalho, por qualquer meio convencional ou eletrônico, para fins de estudo e pesquisa, somente após a publicação de artigo científico, desde que citada a fonte.

De acordo,

Carolina Okamoto Vieira

Aluna

Dra. Ida Sigueko Sano-Martins

Orientadora 
À dra Ida Sigueko Sano Martins, minha querida mãe científica. 
Feliz aquele que transfere o que sabe e aprende o que ensina.

Cora Coralina 


\section{Agradecimentos}

Primeiramente a Deus por estar sempre ao meu lado durante esta caminhada;

À dra Ida Sigueko Sano Martins pela orientação, ensinamentos, incentivo, amizade, carinho, compreensão, apoio e muita paciência;

Ao dr Luis Roberto de Camargo Gonçalves pela ajuda na contenção de serpentes;

Ao dr Benedito Carlos Prezoto por permitir o uso do tromboelastômetro Rotem;

À dra Marta Maria Antoniazzi por permitir e auxiliar no uso do microscópio eletrônico e à Beatriz Maurício por também auxiliar no uso do microscópio;

Ao dr Paulo Flavio Silveira por permitir o uso do fluorímetro e à dra Rafaela F. A. Vendrame pelo auxílio nas leituras;

À dra Maria Cristina Breno por permitir a coleta de sangue de suas serpentes;

Ao Laboratório de Herpetologia do Instituto Butantan e à Recepção de Animais do Laboratório Especial de Coleções Zoológicas pelo fornecimento das serpentes;

À querida amiga Sâmella Oliveira pela amizade, carinho e auxílio;

Ao André F. Alves pela ajuda constante e amizade;

À Luana Senise pela colaboração nos testes de fibrina de rato e pela amizade;

Aos amigos do Laboratório de Fisiopatologia: Tati Lima, Camila T, Karina Kodama, Márcio Yano, Priscila Ozzetti, Jeferson Carrilho, Isabelle e Daliléia por toda a ajuda, carinho e amizade;

Aos funcionários do Laboratório de Fisiopatologia: Jane, Edna, Neusa, Meire, Gleide, Leni, Juscelino e Manoel pelo carinho e auxílio;

A todos do Laboratório de Fisiopatologia e do Instituto Butantan que me ajudaram de alguma forma;

A todos do Departamento de Fisiologia do IB-USP e, em especial, à Roseli;

A todos da Secretaria de Pós Graduação do IB-USP;

À Coordenação de Aperfeiçoamento de Pessoal de Nível Superior (Capes) e ao Conselho Nacional de Desenvolvimento Científico e Tecnológico (CNPq) pelo auxílio financeiro;

Aos meus amores Júlio, Dudu e Sephora por tudo! Pelo amor, carinho, apoio, amizade e muita paciência;

Aos meus pais Luiza e Luiz (in memoriam);

Aos queridos Etsuko (in memoriam), Raul, Flora, Taka, Ana Angélica e Tomaz pelo amor incondicional e apoio sempre! 


\section{CERTIFICADO}

Certificamos que o Projeto intitulado "Estudo do mecanismo de coagulação sanguínea na serpente Crotalus durissus terrificus (Linnaeus,1758) (Ophidia: Viperidae, (Crotalinae)" protocolo $\mathbf{n}^{0} 788 / 11$, sob a responsabilidade de Ida Sigueko Sano-Martins e Carolina Okamoto Vieira, está de acordo com os Princípios Éticos na Experimentação Animal adotado pelo Colégio Brasileiro de Experimentação Animal (COBEA), e foi aprovado pela COMISSÃO DE ÉTICA NO USO DE ANIMAIS DO INSTITUTO BUTANTAN (CEUAIB) em reunião de 10/02/ 2011.

We certify that the research entitled "Study of mechanism of blood coagulation in Crotalus durissus terrificus snake (Linnaeus,1758) (Ophidea: Viperidae, Crotalinae)", protocol $n^{\circ} 788 / 11$, under the responsibility of Ida Sigueko Sano-Martins and Carolina Okamoto Vieira, is in agreement with the Ethical Principles in Animal Research, adopted by the Brazilian College of Animal Experimentation, and was approved by the ETHICAL COMMITTEE FOR ANIMAL RESEARCH of BUTANTAN INSTITUTE in the meeting of 02/10/2011.

\begin{tabular}{|c|c|}
\hline $\begin{array}{c}\text { Vigência do Projeto: } \\
03 / 2011-12 / 2014\end{array}$ & $\mathbf{N}^{\circ}$ de animais/espécie \\
\hline Laboratório de Fisiopatologia & 12 serpentes Crotalus durissus terrificus \\
\cline { 2 - 2 } &
\end{tabular}

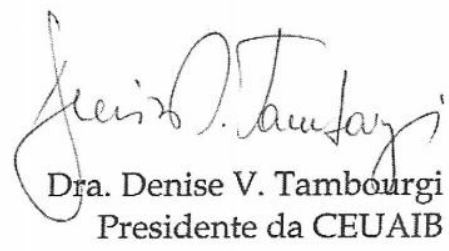




\section{COMISSÃO DE ÉTICA NO USO DE ANIMAIS}

\section{INSTITUTO BUTANTAN}

Av. Dr. Vital Brazil, 1500, CEP 05503-900, São Paulo, SP, Brazil Telefone: (55) (011) 2627-9585 - Fax: (55) (011) 2627-9505 ceuaib@butantan.gov.br

\section{CERTIFICADO}

Certificamos que o projeto intitulado "Estudo do mecanismo de coagulação sanguinea na serpente Crotalus durissus terrificus (Linnaeus,1758) (Ophidia: Viperidae, Crotalinae)", protocolo $\mathrm{n}^{\circ}$ 788/11, sob a responsabilidade de Ida Sigueko Sano Martins e Carolina Okamoto Vieira - que envolve a criação e/ou utilização de animais pertencentes ao filo Chordata, subfilo Vertebrata (exceto o homem), para fins de pesquisa científica - está de acordo com os preceitos da Lei n ${ }^{0} 11.794$, de 8 de outubro de 2008, do Decreto 6.899, de 15 de julho de 2009 e de normas complementares, bem como está de acordo com os Princípios Éticos na Experimentação Animal adotado pelo Colégio Brasileiro de Experimentação Animal (COBEA), e foi aprovado pela COMISSÃO DE ÉTICA NO USO DE ANIMAIS DO INSTITUTO BUTANTAN (CEUAIB) em reunião de 19/02/2014.

This is to certify that the proposal "Study of mechanism of blood coagulation in Crotalus durissus terrificus snake (Linnaeus,1758) (Ophidea: Viperidae, Crotalinae)", protocol n 788/11, under the responsibility of Ida Sigueko Sano Martins and Carolina Okamoto Vieira which involves the breeding and/or use of animals belonging to phylum Chordata, subphylum Vertebrata (except human beings) - has been reviewed by the Institute Butantan Animal Care and Use Committee and approved in 2/19/2014. This proposal is in accordance with standards outlined by Brazilian laws for use of experimental animals, and with ethical principles adopted by the Brazilian College of Animal Experimentation.

\begin{tabular}{|c|c|c|}
\hline $\begin{array}{c}\text { Vigência do Projeto: } \\
03 / 2011-12 / 2014\end{array}$ & $\mathbf{N}^{\circ}$ de animais/espécie & Observação \\
\hline Laboratório de Fisiopatologia & $\begin{array}{c}4 \text { serpentes Crotalus durissus terrificus, } \\
\text { adultas, 600 a } 1000 \mathrm{~g} \text { - adicional } \\
12 \text { serpentes Crotalus durissus terrificus }\end{array}$ & Adicional de animais \\
\cline { 2 - 3 } & &
\end{tabular}

São Paulo, 7 de março de 2014

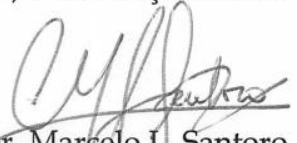

Dr. Marcelo L. Santoro Coordenador da CEUAIB 


\section{Lista de Figuras}

Figura 1. Serpente Crotalus durissus terrificus 16

Figura 2. Distribuição geográfica do gênero Crotalus no Brasil __ 17

Figura 3. Modelo esquemático da ultraestrutura das plaquetas _ 20

Figura 4. Fase de Iniciação __ 21

Figura 5. Fase de Amplificação___ 22

Figura 6. Fase de Propagação ___ 23

Figura 7. Diagrama esquemático das três pares de cadeias polipeptídicas de fibrinogênio

Figura 8. Esquema da formação de fibrina e sua polimerização___ 25

Figura 9. Esquema da polimerização da fibrina e fibrinólise __ 27

Figura 10. Parâmetros primários da tromboelastometria __ 39

Figura 11. Funcionamento do equipamento ImpactR _ 42

Figura 12. Representação gráfica de ensaio de tromboelastometria realizado em sangue

de uma serpente Crotalus durissus terrificus _ 50

Figura 13. Efeito dos polifosfatos na ativação do sangue de uma serpente Crotalus durissus terrificus

Figura 14. A) Representação gráfica da agregação trombocitária com colágeno 2,5 $\mu \mathrm{g} / \mathrm{mL}$ em sangue total citratado da serpente Crotalus durissus terrificus e em B) da agregação trombocitária com ionóforo de cálcio $0,02 \mathrm{M}$ em plasma rico em trombócito

Figura 15. Representação gráfica da agregação trombocitária com ADP $50 \mu \mathrm{M}$ : A) em plasma rico em trombócitos; B) em sangue total citratado da serpente Crotalus durissus terrificus.

Figura 16. Adesividade trombocitária em ImpactR _ 55

Figura 17. Detecção inulogógica comparativa dos fatores plasmáticos FVII e FXII entre plasma de serpente C.d.terrificus e humano em Western Blotting 56

Figura 18. Microscopia eletrônica de varredura de plasma rico em trombócitos da C.d.terrificus 58

Figura 19. Microscopia eletrônica de varredura de trombócito aderido em superfície de vidro 58

Figura 20. Microscopia eletrônica de varredura de coágulo de fibrina 60 


\section{Lista de Tabelas}

Tabela 1. Valores hematológicos e índices hematimétricos médios do sangue da serpente Crotalus durissus terrificus $(\mathrm{n}=17)$.

Tabela 2. Valores médios dos parâmetros de coagulação realizados em sangue da serpente Crotalus durissus terrificus.

Tabela 3. Valores médios dos tempos de trombina (TT) em plasma de Crotalus durissus terrificus, em segundos.

Tabela 4. Parâmetros de coagulação obtido da análise por tromboelastometria em sangue da serpente Crotalus durissus terrificus $(n=8)$.

Tabela 5. Parâmetros de coagulação obtido da análise por tromboelastometria em sangue da serpente Crotalus durissus terrificus.

Tabela 6. Parâmetros de agregação trombocitária em sangue total ou PRT da serpente Crotalus durissus terrificus com diferentes agonistas $(\mathrm{n}=5)$.

Tabela 7. Parâmetros da adesividade trombocitária com sangue da serpente Crotalus durissus terrificus $(\mathrm{n}=5)$. 


\section{Sumário}

\subsection{SERPENTES}

1.1.1. CROTALUS DURISSUS TERRIFICUS

1.2. HEMOSTASIA

1.2.1 MODELO DE FORMAÇÃO DE FIBRINA BASEADO EM SUPERFÍCIES CELULARES

1.2.1.1. Plaquetas 18

1.2.1.2. Fase de iniciação da Coagulação 20

1.2.1.3. Fase de amplificação da Coagulação 21

1.2.1.4. Fase de propagação da Coagulação 22

1.2.2. FIBRINOGÊNIO E ESTRUTURA DA FIBRINA 23

1.2.3. INIBIDORES DA COAGULAÇÃO 26

1.3. SISTEMA FIBRINOLÍTICO 2

1.4. Polifosfatos E heMOSTASia

1.5. Hemostasia COMPARAda 29

2. OBJETIVOS $\quad 32$

3. MATERIAIS E MÉTODOS

$\begin{array}{lr}\text { 3.1. MATERIAIS } & 34\end{array}$

3.1.1. ANIMAIS $\quad 34$

3.2. MÉTODOS $r$

3.2.1. COLETA E AMOSTRAS DE SANGUE 234

3.2.2. TROMBOPLASTINA $\quad 34$

3.2.3. PARÂMETROS HEMATOLÓGICOS

3.2.3.1. Contagem global de eritrócitos, leucócitos e trombócitos 35

3.2.3.2. Determinação do Hematócrito $\quad 35$

3.2.3.3. Dosagem de Hemoglobina $\quad 35$

3.2.3.4. Cálculo dos índices hematimétricos 36

3.2.4. DOSAGEM DO FIBRINOGÊNIO

3.2.5. TESTES DE COAGULAÇÃOO 36

3.2.5.1. Tempo de Coagulação (TC) 37

3.2.5.2. Retração do Coágulo $\quad 37$

3.2.5.3. Tempo de Protrombina (TP) 37

3.2.5.4. Tempo de Recalcificação $\quad 37$

3.2.5.5. Tempo de Tromboplastina Parcial Ativada (TTPA) 38

3.2.5.6. Tempo de Trombina (TT) 38

$\begin{array}{ll}\text { 3.2.6. TROMBOELASTOMETRIA } & 38\end{array}$

$\begin{array}{ll}3.2 .6 .1 \text { Natem } & 39\end{array}$

$\begin{array}{lr}3.2 .6 .2 . & 39\end{array}$

$\begin{array}{ll}3.2 .6 .3 . \text { Intem } & 39\end{array}$

$\begin{array}{lr}\text { 3.2.6.3.1 Intem com Polifosfato } & 40\end{array}$

$\begin{array}{lr}\text { 3.2.6.4. Fibtem } & 40\end{array}$

3.2.7. AGREGAÇÃO TROMBOCITÁRIA 40

3.2.8. ADESÃO TROMBOCITÁRIA $\quad 41$

3.2.9. MICROSCOPIA ELETRÔNICA DE VARREDURA 42

3.2.9.1. Preparação de plasma rico em trombócitos e trombócitos aderidos 42 
3.2.9.2. Preparação de agregados trombocitários

3.2.9.3. Preparação do coágulo de fibrina para estudo da morfologia ultraestrutural da fibrina 43

3.2.9.4. Processamento das amostras para microscopia eletrônica de varredura 43

3.2.10. DETECÇÃO IMUNOLÓGICA DOS FATORES VII E FXII 44

3.2.10.1. Eletroforese em Gel de Poliacrilamida (SDS-PAGE) 44

3.2.10.2. Western Blotting $\quad 44$

$\begin{array}{lr}\text { 4. RESULTADOS } & 47\end{array}$

4.1.PARÂMETROS heMATOLÓGICOS 47

4.2. TESTES DE COAGULAÇ̃̃OO

4.2.1 TEMPO DE TROMBINA 48

4.3 TROMBOELASTOMETRIA

4.3.1. PARTICIPAÇÃO DOS POLIFOSFATOS NA HEMOSTASIA

4.4. AGREGAÇÃO TROMBOCITÁRIA

4.5. ADESÃO TROMBOCITÁRIA

4.6. DETECÇÃO IMUNOLÓGICA DOS FATORES VII E FXII 56

4.7. MICROSCOPIA ELETRÔNICA DE VARREDURA

\begin{tabular}{lr} 
5. DISCUSSÃO & 63 \\
\hline
\end{tabular}

6. CONCLUSÕES

\begin{tabular}{ll} 
7. RESUMO & 73 \\
\hline
\end{tabular}

8. ABSTRACT $\quad 75$

\begin{tabular}{lr}
.APENNDICE A - ABREVIATURAS & 77 \\
\hline
\end{tabular}

10. APÊNDICE B - FATORES DA COAGULAČ̃̃O

11. REFERÊNCIAS BIBLIOGRÁFICAS $\quad 81$ 


\section{INTRODUÇÃO}




\section{Introdução}

\subsection{Serpentes}

As serpentes são caracterizadas pela forma alongada do corpo, escamas epidérmicas por todo o corpo e também pela ausência de membros locomotores, pálpebras móveis e de ouvido externo (Melgarejo, 2003).

As serpentes pertencem à Classe Reptilia, Ordem Squamata e à Subordem Ophidia. As serpentes são encontradas em quase todos os ambientes, exceto nas calotas polares (Franco, 2003). Há aproximadamente 2900 espécies de serpentes, organizadas em três Superfamílias: Typhlopoidea (Scolecophidia), Henophidia (Booidea) e Xenophidia (Colubroidea) (Zug, Vitt e Caldwell, 2001).

O Brasil possui cerca de 270 espécies de serpentes. Destas, somente as famílias Elapidae e Viperidae são peçonhentas, ou seja, aquelas que apresentam aparelhos apropriados para inocular toxinas produzidas em glândulas especializadas. A família Viperidae é constituída de três subfamílias: Viperinae, Azemiopinae e Crotalinae (Franco, 2003). Essa família tem cerca de 250 espécies distribuídas pelo mundo, sendo que 30 dessas espécies estão no Brasil (Melgarejo, 2003).

Dentre os viperídeos, a subfamília Crotalinae apresenta fosseta loreal como característica exclusiva. A fosseta loreal é um orifício situado entre o olho e a narina, sendo revestido por epitélio termossensível que capta variações de temperatura do ambiente (Kraus, Mink e Brown, 1996).

\subsubsection{Crotalus durissus terrificus}

O gênero Crotalus abrange um grupo diversificado na América do Norte, embora no Brasil apresente uma única espécie, Crotalus durissus, que tem reconhecidas cinco subespécies, três das quais com ampla dispersão (Wuster et al., 2005).

A serpente Crotalus durissus terrificus (C.d. terrificus) (Figura 1) é encontrada na região Sul e se estende pelo Oeste, até algumas áreas abertas de Mato Grosso, Rondônia, Amazonas e Pará. Há também a Crotalus durissus cascavella típica das 
caatingas, Crotalus durissus collilineatus, distribuída em São Paulo, Mato Grosso, Minas Gerais, Distrito Federal e Goiás, Crotalus durissus ruruima, presente em Roraima e, finalmente, a Crotalus durissus marajoensis, presente na Ilha de Marajó, no Pará (Figura 2) (Melgarejo, 2003).

As serpentes do gênero Crotalus do Brasil são terrestres, robustas, pouco ágeis e apresentam o guizo na cauda como característica principal. Popularmente são conhecidas como cascavéis. São vivíparas e, em média, podem ter ninhada de 6 a 22 filhotes (Melgarejo, 2003). São encontradas em campos abertos, áreas secas, arenosas e pedregosas e raramente na faixa litorânea. Não têm por hábito atacar e, quando excitadas, denunciam sua presença pelo ruído característico do guizo ou chocalho (Funasa, 2001).

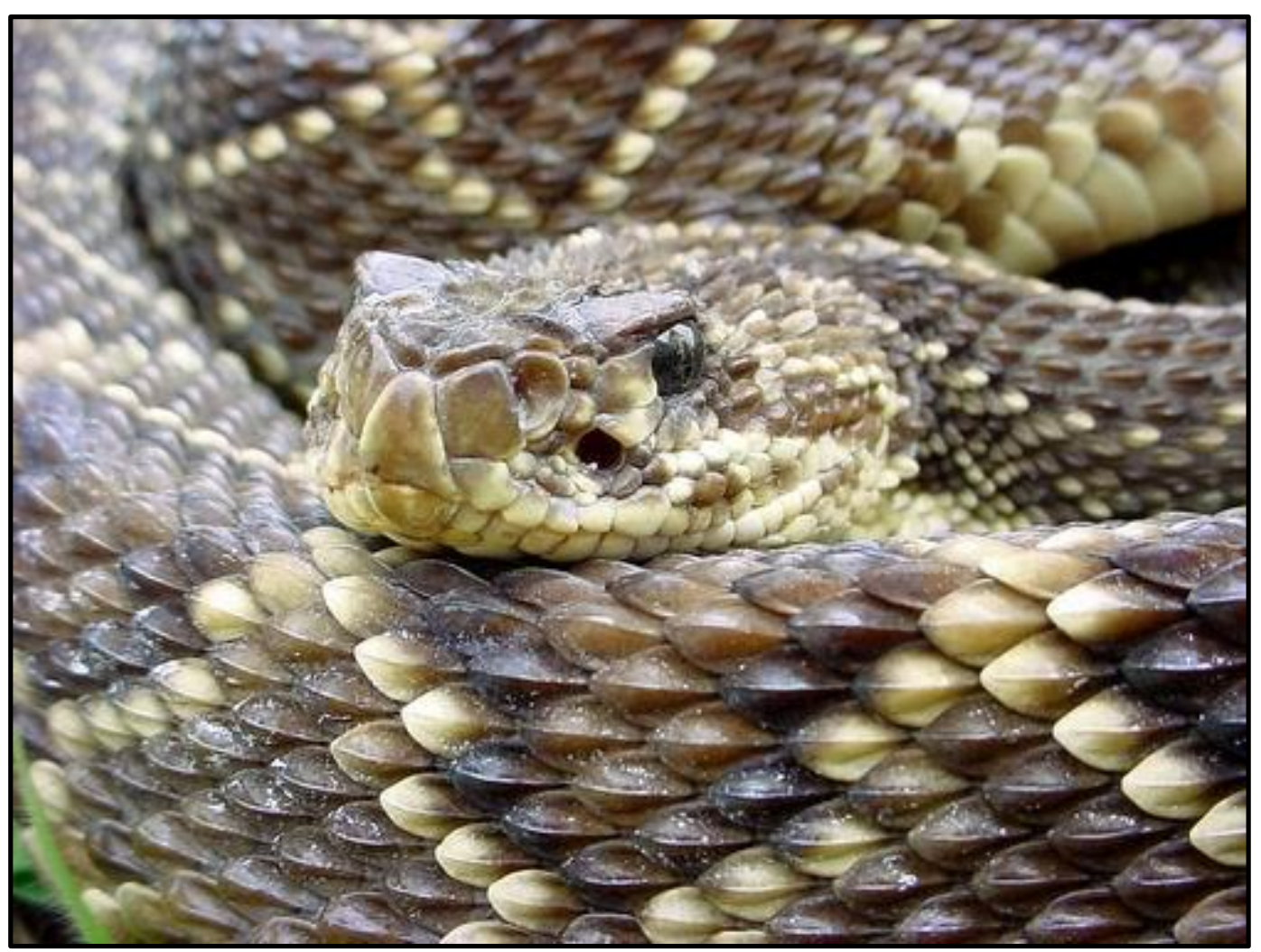

Figura 1. Serpente Crotalus durissus terrificus (foto gentilmente cedida por Yuri Fanchini Messas). 


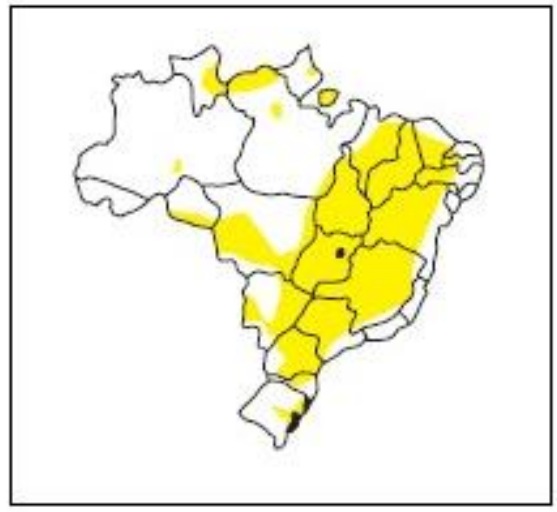

Figura 2. Distribuição geográfica do gênero Crotalus no Brasil (Funasa, 2001).

Os viperídeos representam o grupo de serpentes mais importante para a Saúde Pública, pois são responsáveis pela maioria dos acidentes ofídicos registrados no Brasil. Cerca de $7 \%$ do total de acidentes ofídicos são causados pelas serpentes do gênero Crotalus, sendo o responsável pelo maior número de óbitos (1 \%) (Sinan, 2014).

\subsection{Hemostasia}

A hemostasia é um mecanismo fundamental de todos os vertebrados e apresenta diversas funções importantes: manter o sangue em estado fluido enquanto ele circula pelo sistema vascular; conter a hemorragia no local da lesão e evitar a perda de sangue através da formação de um tampão hemostático; limitar o processo para a região do dano; e garantir a remoção do tampão quando a cicatrização é completa. Este processo depende do delicado balanço e de inter-relações complexas entre pelo menos cinco componentes: vasos sanguíneos, plaquetas, proteínas e inibidores da coagulação e sistema fibrinolítico (Brosovic, 1991; Gentry, 2004; Laffan e Manning, 2011).

\subsubsection{Modelo de formação de fibrina baseado em superfícies celulares}

A cascata de coagulação clássica, proposta por Macfarlane e Davie e Ratnoff (Davie e Ratnoff, 1964; Macfarlane, 1964), consiste em uma ativação em cadeia, na qual cada fator ativado permite a ativação de um fator seguinte, resultando na geração de trombina e consequente clivagem do fibrinogênio, formando monômeros de fibrina. Essa cascata é dividida didaticamente em duas vias, intrínseca e extrínseca.

Apesar deste modelo de cascata tradicional explicar como o processo de coagulação ocorre in vitro, o processo hemostático in vivo não é explicado 
adequadamente. Assim, tem sido proposto um novo modelo de coagulação baseado em superfícies celulares (Hoffman, 2003; Smith, 2009).

O novo modelo considera a participação das células no mecanismo hemostático, que ocorre em etapas distintas (iniciação, amplificação e propagação), mas sobrepostas, exigindo a participação de plaquetas e células carreadoras de fator tissular. Ao integrar a participação das células à coagulação, esse modelo explica como a coagulação ocorre em um sistema vascular dinâmico e também explica o papel específico dos sítios de ligação das plaquetas com as proteínas da coagulação (Smith, 2009).

A velocidade das reações enzimáticas da cascata depende da presença de uma superfície de membrana apropriada. Algumas proteínas da coagulação (fatores VII, IX, $\mathrm{X}$, II, proteína $\mathrm{C}$ e proteína $\mathrm{S}$ ) contêm resíduos de ácido glutâmico, que permitem a ligação da proteína com a superfície de membrana através da interação com cálcio e fosfolipídios carregados negativamente (Smith, 2009). Após uma lesão, as células expõem esses fosfolipídios na membrana. A exposição destes fosfolipídios aumenta a velocidade de algumas reações da coagulação e também torna a superfície da célula uma superfície pró-coagulante. Por outro lado, células em repouso são incapazes de sustentar a cascata de coagulação devido à reduzida velocidade de reações em membranas que não contêm fosfolipídio. Além disso, as células em repouso expressam anticoagulantes em sua superfície, como proteoglicanas, trombomodulina e inibidor da via do fator tissular (TFPI) (Sagripanti e Carpi, 2000; Levi, Ten Cate e Van Der Poll, 2002; Schouten et al., 2008).

\subsubsection{Plaquetas}

Em mamíferos, as plaquetas são partículas anucleadas, formadas a partir da fragmentação citoplasmáticas de megacariócitos. Elas apresentam de 2 a $5 \mu \mathrm{m}$ de diâmetro e $0,5 \mu \mathrm{m}$ de espessura. $\mathrm{O}$ número de plaquetas circulantes em mamíferos varia de 150 a mais de $1000 \times 10^{9}$ plaquetas por litro, de acordo com a espécie (White, 2011).

As plaquetas apresentam quatro regiões morfologicamente distintas: zona periférica, zona sol-gel, sistema de membranas e zona de organelas (Figura 3). A zona periférica é formada pela membrana plasmática, composta pela bicamada fosfolipídica, importante superfície aniônica para as plaquetas ativadas, e glicocálice. O glicocálice é 
constituído principalmente de glicoproteínas que atuam como receptores, que permitem a adesão plaquetária à superfície lesada, iniciam a ativação plaquetária, promovem a agregação plaquetária e aceleram o processo de coagulação. Os principais receptores são GP Ib-IX-V e GP IIb-IIIa (White, 2011). A zona sol-gel é constituída por microtúbulos, microfilamentos, glicogênio e vesículas. Os microtúbulos dão sustentação ao citoesqueleto e os filamentos de actina e miosina estão envolvidos na mudança de forma, transformação interna e retração do coágulo (Escolar, Krumwiede e White, 1986). O sistema de membranas é formado pelo complexo de Golgi, sistema de canais abertos, sistema tubular denso, complexo de membranas e retículo endoplasmático rugoso. A zona de organelas é composta por a grânulos, corpos densos, peroxissomos, lisossomos e mitocôndrias. Os $\alpha$ grânulos são os mais numerosos, sendo de 40 a 80 por plaqueta, com diâmetro variando de 200 a 500 nm. Os a grânulos contém proteínas como fator de von Willebrand, fibrinogênio, fibronectina, vitronectina e trombospondina (Wencel-Drake et al., 1985). Os corpos densos são menores e menos numerosos que os a grânulos. A principal característica deles é a alta densidade eletrônica, sendo comumente esféricos e elétron opacos. Dependendo da ativação, as plaquetas liberam dos corpos densos ADP, ATP, aminas biogênicas (como serotonina), polifosfatos e cátions divalentes, principalmente cálcio (White, 2011).

As plaquetas desempenham papel fundamental na hemostasia, aderindo ao subendotélio e umas às outras, formando o tampão plaquetário (Wei et al., 2009). Após a lesão, as plaquetas ligam-se a proteínas adesivas, como o colágeno, através de receptores de superfície (adesão plaquetária), mudam de forma e emitem pseudópodes. O fator de von Willebrand adere-se às fibras de colágeno, mudando sua conformação. Em seguida, as plaquetas ligam-se ao fator de von Willebrand através de glicoproteínas de membrana GP Ib-IX. Após a adesão na superfície da lesão, as plaquetas mudam de forma, emitem pseudópodes, aderem-se umas às outras (agregação plaquetária) e liberam compostos biologicamente ativos armazenados nos grânulos plaquetários, incluindo ADP, serotonina, tromboxano $\mathrm{A}_{2}\left(\mathrm{TXA}_{2}\right), \beta$ tromboglobulina $(\beta \mathrm{TG})$, fator 4 plaquetário (PF4), fibrinogênio e fator de von Willebrand. Essas substâncias liberadas reforçam a agregação de plaquetas. $\mathrm{O}$ TXA 2 é um indutor bastante potente da secreção e agregação plaquetária, sendo formado a partir de ácido araquidônico pela enzima ciclooxigenase. $\mathrm{O}$ ácido araquidônico é liberado da membrana das plaquetas por fosfolipases 
após a ativação das plaquetas. O fibrinogênio permite a agregação de plaquetas através da ligação com receptores GP IIb-IIIa (Hiller, 2007).

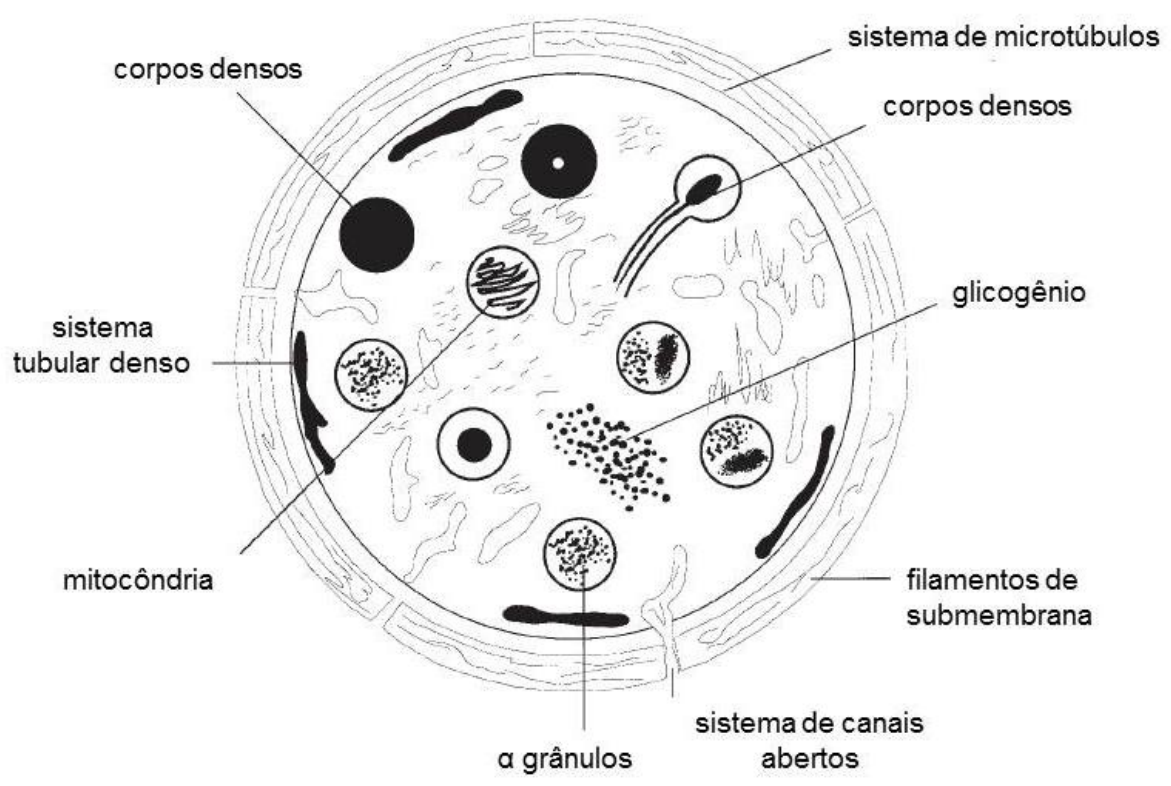

Figura 3. Modelo esquemático da ultraestrutura das plaquetas (Hiller, 2007).

\subsubsection{Fase de iniciação da Coagulação}

O fator tissular desempenha importante função em muitos processos biológicos, sendo possivelmente o iniciador mais relevante da coagulação in vivo. É a única proteína da coagulação permanentemente unida a uma superfície de membrana sendo, portanto, a etapa de iniciação localizada em células que expressam o fator tissular (Hoffman e Monroe, 2001; Morrissey e Mutch, 2006). Em condições normais, o fator tissular não está na circulação, prevenindo o início da coagulação.

Após uma lesão vascular, o fator tissular é exposto e rapidamente liga-se ao fator VIIa que circula em baixas concentrações já ativado (Morrissey, 1996; Morrissey e Mutch, 2006). Todas as outras proteínas da coagulação circulam como zimogênios. O complexo formado pelos fatores tissular e VIIa ativam os fatores IX e X. O fator Xa associado ao seu cofator, fator $\mathrm{Va}$, forma o complexo protrombinase na superfície da célula carreadora de fator tissular (Figura 4) (Monroe, Hoffman e Roberts, 1996). 


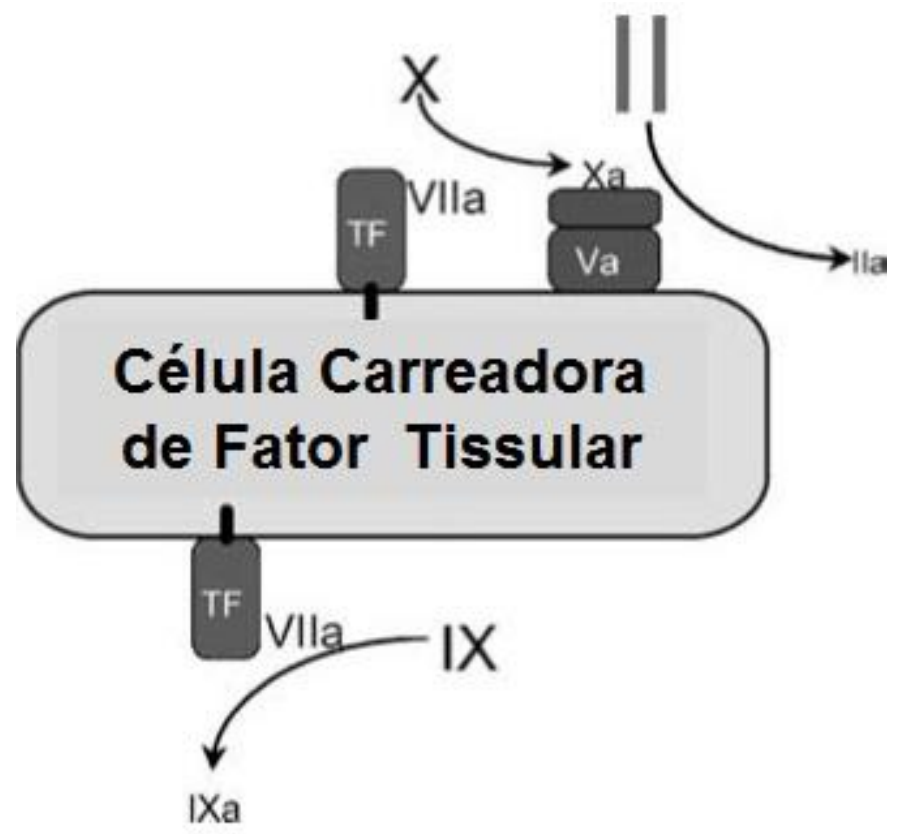

Figura 4. Fase de Iniciação. Essa fase ocorre na célula carreadora de fator tissular e é iniciada com a exposição do fator tissular, após a lesão. Essa fase resulta na geração de pequena quantidade de FIXa e IIa (trombina) (Hoffman, 2003). TF: fator tissular.

\subsubsection{Fase de amplificação da Coagulação}

A pequena quantidade de trombina, gerada na superfície da célula carreadora de fator tissular durante a fase de iniciação, liga-se a receptores na superfície das plaquetas, resultando na mudança de forma das plaquetas, rearranjo da membrana fosfolipídica, criando uma superfície de membrana pró-coagulante, e liberação do conteúdo granular. Além de ativar as plaquetas, a trombina cliva o fator XI em XIa e o fator V em Va, na superfície das plaquetas. A trombina ainda cliva o fator de von Willebrand ligado ao fator VIII, liberando-o para mediar a adesão e agregação plaquetária. O fator VIII livre é ativado pela própria trombina em FVIIIa (Figura 5) (Hoffman, 2003; Smith, 2009). 


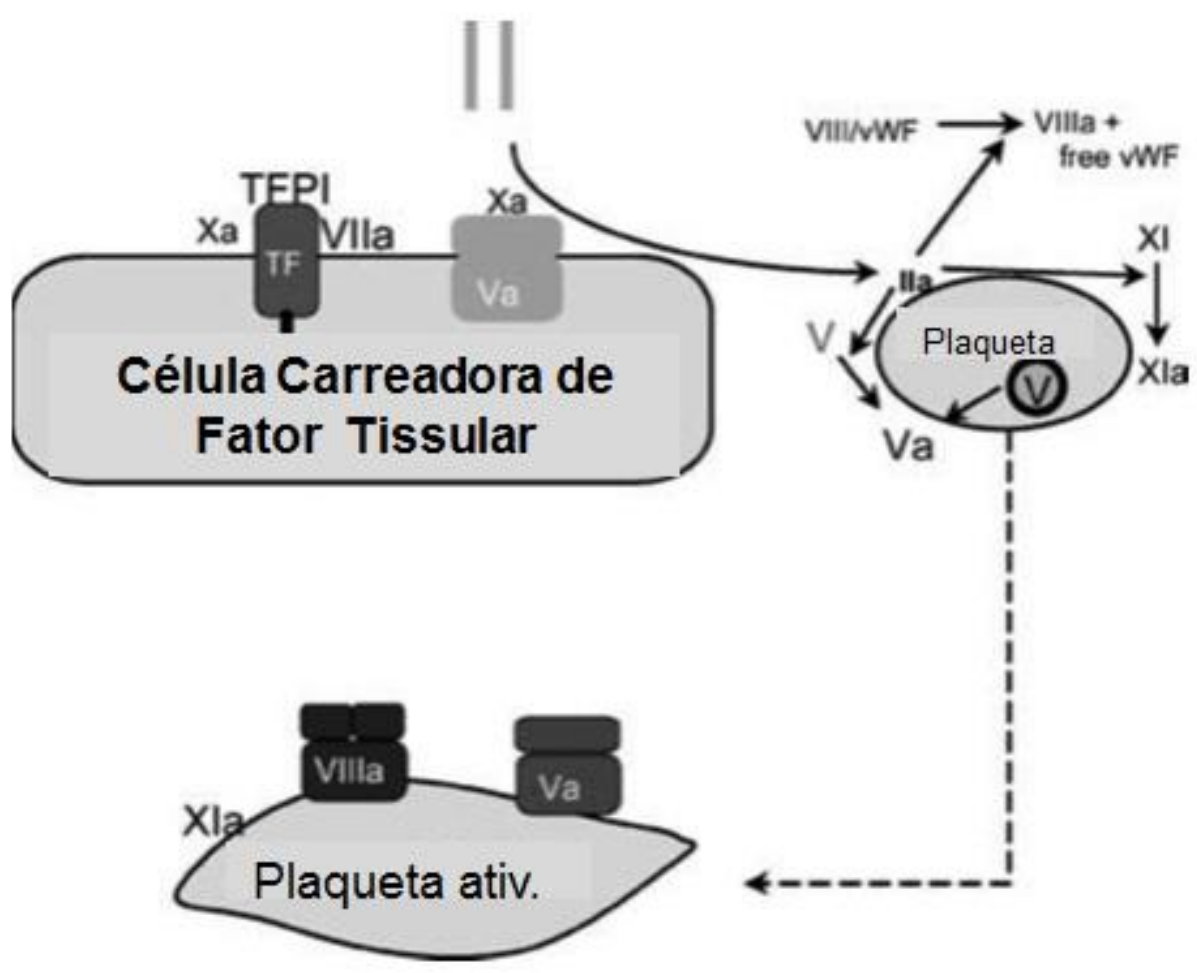

Figura 5. Fase de Amplificação. A pequena quantidade de trombina gerada ativa as plaquetas, libera fator de von Willebrand e permite a ativação dos fatores V, VIII e XI (Hoffman, 2003). Plaqueta ativ.: plaqueta ativada; vwF: fator de von Willebrand; TAFI: inibidor da fibrinólise ativado pela trombina; TFPI: inibidor da via do fator tissular.

\subsubsection{Fase de propagação da Coagulação}

Com a pequena quantidade de plaquetas ativadas na fase de amplificação, ocorre a liberação do conteúdo granular, o que resulta em um recrutamento de um número maior de plaquetas para o local da lesão. A exposição de receptores de glicoproteínas na superfície das plaquetas resulta na interação célula-célula, permitindo a agregação plaquetária.

A fase de propagação ocorre na superfície dessas plaquetas. Na superfície das plaquetas ativadas, o fator IXa, gerado na fase de iniciação, liga-se ao fator VIIIa na superfície da plaqueta. Quantidades adicionais de FIXa também são geradas na fase de amplificação, devido à clivagem do fator IX em FIXa. Uma vez formado o complexo tenase intrínseco (FIXa-FVIIIa) na superfície da plaqueta ativada, rapidamente ocorre a geração de fator Xa. O fator Xa rapidamente liga-se ao fator Va (gerado pela trombina 
na fase de amplificação) e cliva a protrombina em trombina (Hoffman, 2003). A atividade protrombinásica resulta em uma grande geração de trombina (Figura 6).

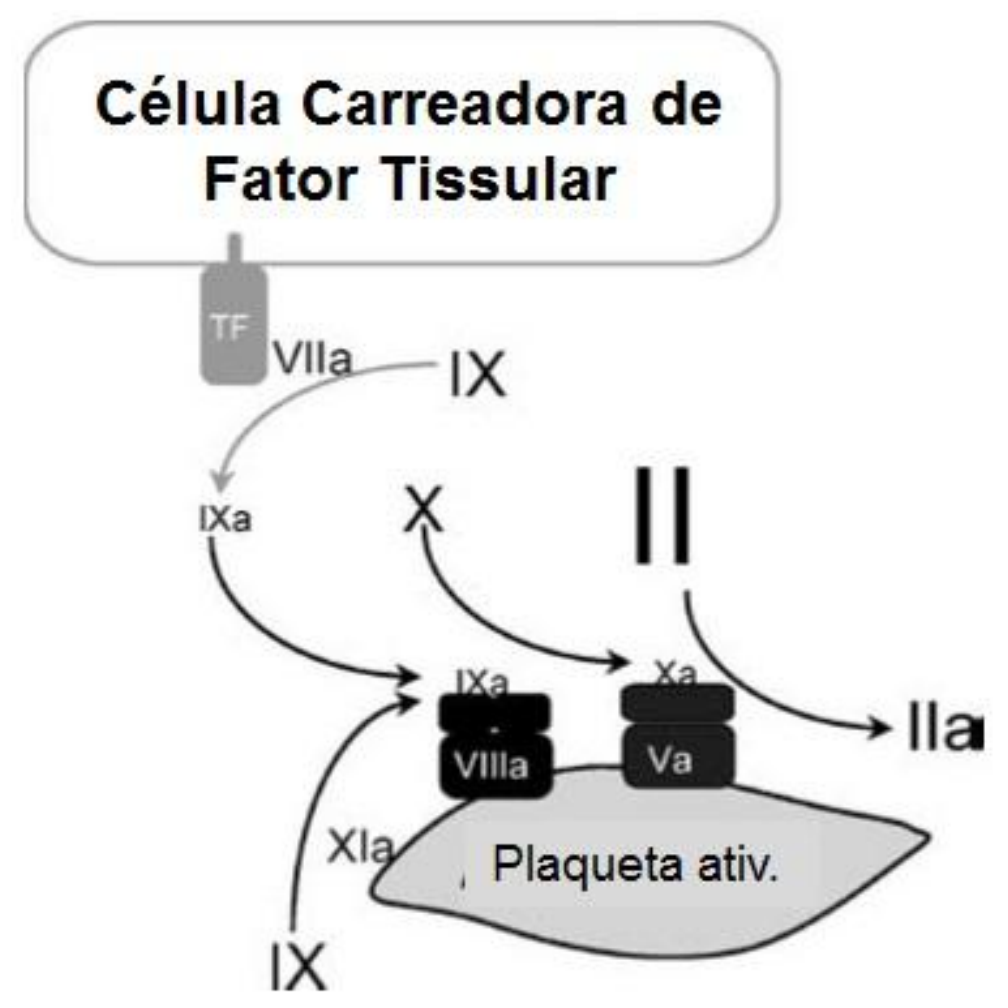

Figura 6. Fase de Propagação. Nessa fase, várias enzimas geradas nas fases anteriores juntam-se na superfície da membrana da plaqueta ativada, formando o complexo tenase intrínseco, que resulta na ativação do fator X. O complexo protrombinase resulta em grande geração de trombina (Hoffman, 2003).

A trombina gerada cliva o fibrinogênio, liberando os fibrinopeptídeos e formando monômeros de fibrina (Smith, 2009). O fator XIII também é ativado pela trombina e catalisa a polimerização desses monômeros, transformando-os em fibrina estável (Figura 7) (Davie e Ratnoff, 1964).

\subsubsection{Fibrinogênio e estrutura da fibrina}

O fibrinogênio é uma glicoproteína composta de três pares de cadeias polipeptídicas, designadas $\mathrm{A} \alpha, \mathrm{B} \beta$ e $\gamma$. As seis cadeias são ligadas por pontes dissulfeto, formando uma molécula de duas metades simétricas. A região aminoterminal de todas as seis cadeias são ligadas por pontes dissulfeto em um domínio central (Gentry, 2004; Tennent et al., 2007; Medved e Weisel, 2009). 


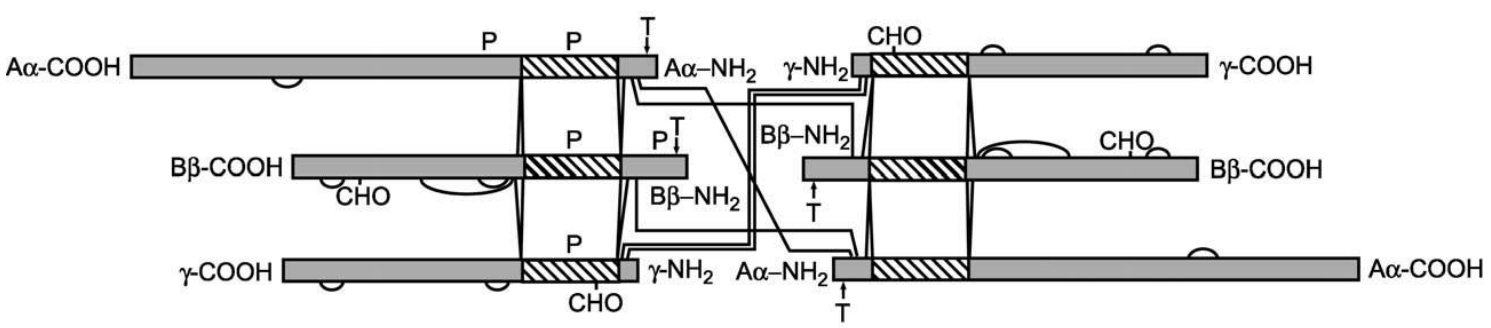

Figura 7. Diagrama esquemático das três pares de cadeias polipeptídicas de fibrinogênio. As cadeias $A \alpha, B \beta$ e $\gamma$ estão representadas por barras com comprimento proporcionais ao número de resíduos de aminoácidos em cada uma das cadeias. As regiões em espiral são indicadas pelas listras diagonais, enquanto que as ligações dissulfeto são indicadas pelas linhas sólidas. Os sítios de clivagem da trombina e plasmina estão indicados por T e P, respectivamente (Weisel, 2005).

A trombina, produzida pela clivagem proteolítica da protrombina pelo fator Xa na presença do fator $\mathrm{V}$ e fosfolipídios, é uma protease que cliva o fibrinogênio nas ligações Arg-Gly das regiões N-terminais das cadeias A $\alpha$ e B $\beta$, liberando os fibrinopeptídeos A e B. A liberação dos fibrinopeptídeos A ocorre mais rapidamente que os fibrinopeptídeos B, mas a medida que a polimerização ocorre, a liberação dos fibrinopeptídeos B aumenta. A remoção dos fibrinopeptídeos expõe os sítios A e B do nódulo central de um monômero de fibrina (fibrina des $\mathrm{AB}$ ), que interagem com os sítios a e b do domínio $\mathrm{D}$, respectivamente, de outro monômero, formando dímeros e trímeros. Dímeros e trímeros de fibrina podem ligar-se formando oligômeros que por sua vez formam protofibrilas, capazes de agregação lateral levando à formação de fibras (Figura 8) ((Weisel e Litvinov, 2013). 

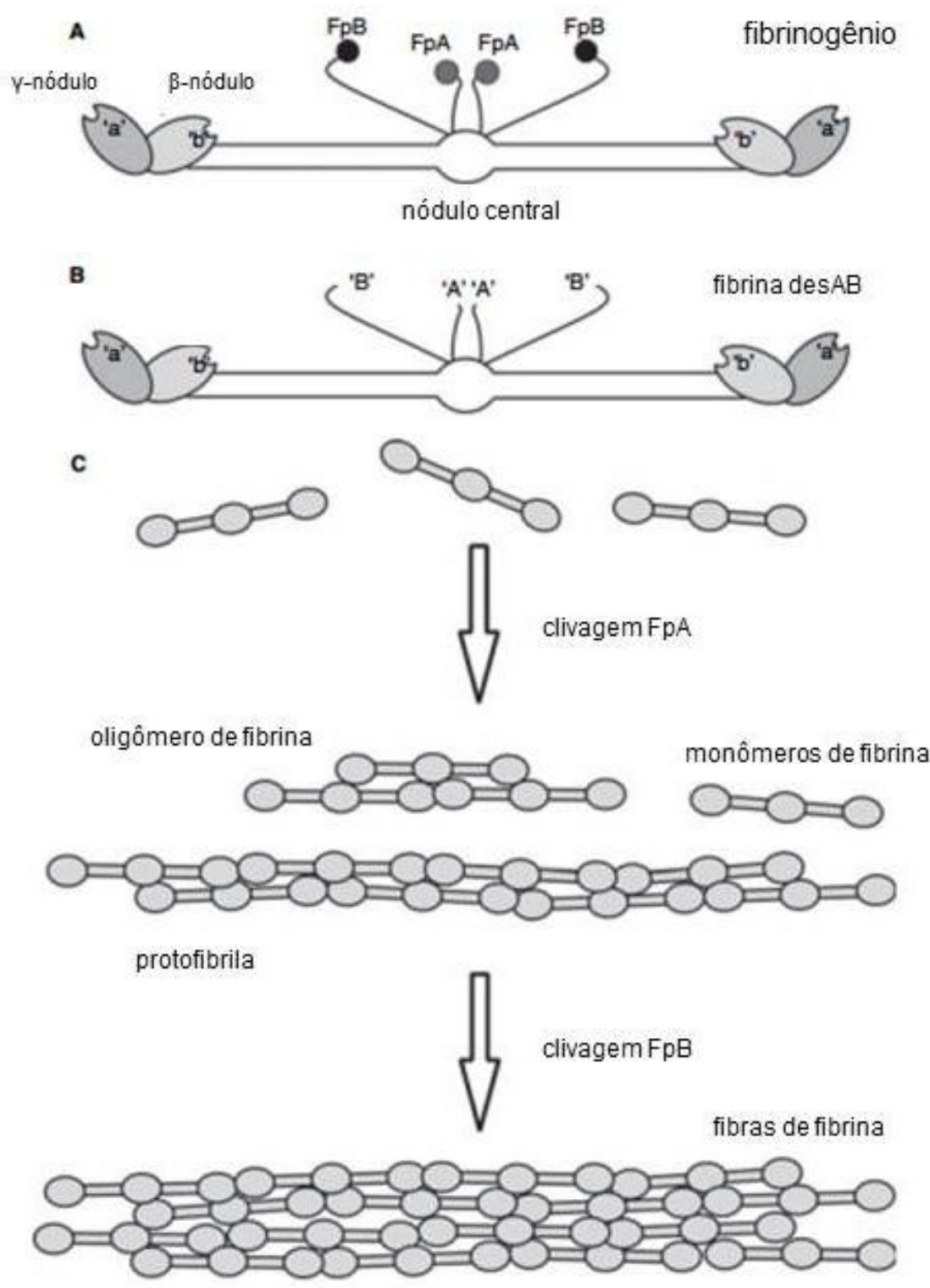

Figura 8. Esquema da formação de fibrina e sua polimerização. A) Fibrinogênio esquemático mostrando os fibrinopeptídeos A e $\mathrm{B}$ (FpA e FpB, respectivamente), presentes nas cadeias $\mathrm{A} \alpha$ e $\mathrm{B} \beta$. B) Formação de monômeros de fibrina. Notar os sítios de polimerização da fibrina complementares A:a e B:b. Os sítios a e b estão presentes na cadeia $\gamma$ enquanto que os sítios $\mathrm{A}$ e $\mathrm{B}$ são expostos após a remoção dos fibrinopeptídeos $\mathrm{A}$ e $\mathrm{B}$, respectivamente (fibrina desAB, que é uma molécula destituída de ambos fibrinopeptídeos). C) Etapas iniciais da polimerização, mostrando oligômeros (polímero constituído de poucos monômeros de fibrina), protofibrilas ou fibrilas (constituídas de dois polímeros de fibrila) e fibras de fibrina (grupos de protofibrilas associados uns aos outros lateralmente) (Medved e Weisel, 2009). 


\subsubsection{Inibidores da Coagulação}

A formação do coágulo de fibrina/plaqueta no local da injúria no processo de coagulação deve ser limitada, evitando a formação de uma oclusão trombótica nas áreas adjacentes. Para isso, vários anticoagulantes estão envolvidos: sistema antitrombinaheparina, proteína $\mathrm{C}$, complexo trombomodulina/trombina, inibidor da fibrinólise ativado pela trombina (TAFI) e inibidor da via do fator tissular (TFPI) (Esmon, 2005).

Em uma lesão vascular, com a ativação da coagulação e geração da trombina, uma parte da trombina gerada liga-se à trombomodulina na superfície das células endoteliais, permitindo a ativação do inibidor TAFI. O TAFI inibe a fibrinólise removendo resíduos de lisina da fibrina durante o processo de lise. O complexo antitrombina-heparina inibe as proteínas dependentes de vitamina $\mathrm{K}$ (IIa, IXa e Xa), com exceção do fator VIIa que circula em pequenas concentrações ativado. A antitrombina inibe também a atividade da trombina e também dos fatores XIa e XIIa O complexo trombomodulina/trombina ativa a proteína $\mathrm{C}$, que se liga ao seu cofator, proteína $\mathrm{S}$, e degrada os fatores Va e VIIa. O TFPI forma um complexo com os fatores tissular, VIIa e Xa, inativando-os. (Elias et al., 1993; Hoffman, 2003; Smith, 2009).

\subsection{Sistema Fibrinolítico}

O sistema fibrinolítico desempenha importante papel na deposição e remoção da fibrina, garantindo a fluidez sanguínea. O plasminogênio, presente no sangue circulante como um zimogênio, quando ativado é convertido para sua forma ativa, a plasmina. Embora seja um processo altamente específico para degradar a fibrina, a plasmina pode degradar também o fibrinogênio e os fatores V e VIII. Por esta razão esta enzima não circula na forma livre, é rapidamente complexada com a $\alpha 2$-antiplasmina, que é o inibidor específico mais importante. São conhecidos dois ativadores de plasminogênio (PA) em mamíferos, o ativador de plasminogênio tecidual (t-PA) e o ativador de plasminogênio uroquinase (u-PA). A inibição do sistema fibrinolítico ocorre tanto pela inibição do plasminogênio pelos inibidores dos ativadores de plasminogênio (PAI-1 e PAI-2), quanto pela inibição da plasmina principalmente pela $\alpha 2$-antiplasmina (Figura 9) (Collen, 1999). 


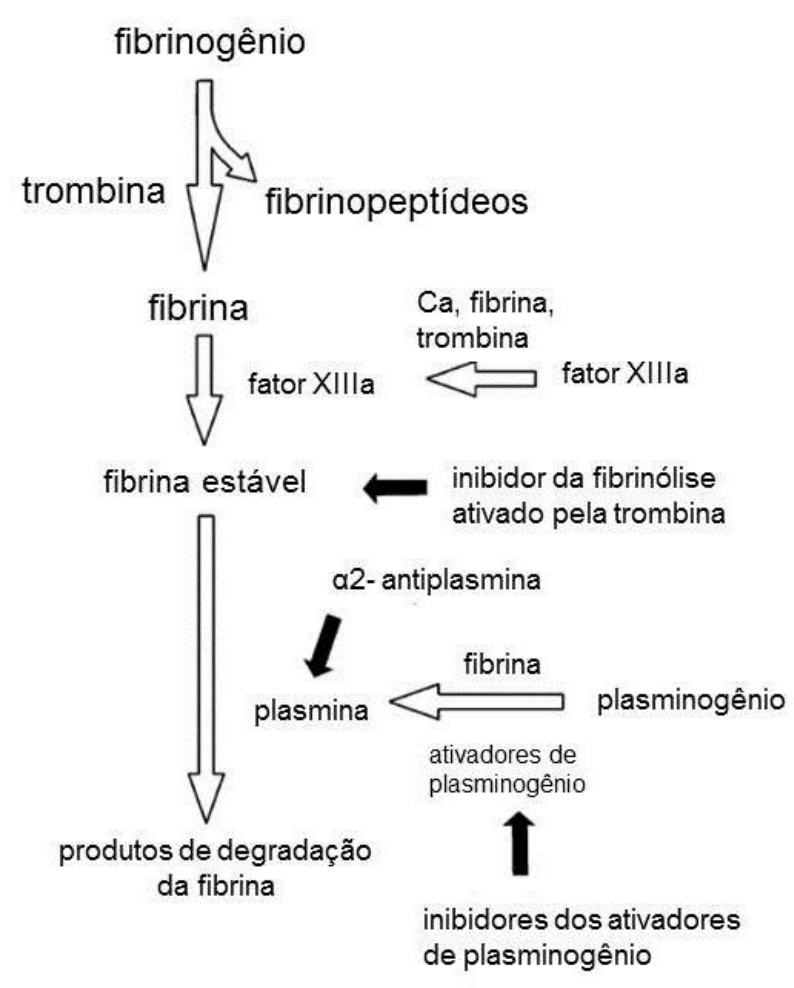

Figura 9. Esquema da polimerização da fibrina e fibrinólise (Weisel, 2005).

\subsection{Polifosfatos e hemostasia}

Os polifosfatos (polyP) são polímeros lineares de resíduos de fosfatos inorgânicos, que podem variar de dez a centenas, ligados por pontes fosfoanidrido. Os polyP são ubíquos e abundantes na natureza, sendo encontrados em uma grande variedade de células, desde bactérias, fungos, protozoários e outros microrganismos até vegetais e animais (Kulaev e Vegabov, 1983; Wood e Clark, 1988; Ruiz et al., 2004). As bactérias, assim como muitos eucariotos unicelulares, acumulam polyP em grânulos conhecidos como acidocalcissomos.

Recentemente, os polifosfatos foram observados nos corpos densos das plaquetas humanas (Ruiz et al., 2004; Muller et al., 2009). Assim como os acidocalcissomos de bactérias, os corpos densos são esféricos, ácidos (Dean et al., 1984), eletrondensos (White, 1969) e contêm íons divalentes, incluindo o cálcio, magnésio e zinco (Fukami et al., 1980). Os polyP das plaquetas apresentam de 60 a 100 unidades de fosfato e estão em concentração de $0,74 \pm 0,08 \mu \mathrm{mol}$ de polyP/ $10^{11}$ plaquetas. Considerando que o sangue humano possui de 1,5 a $4,5 \times 10^{11}$ plaquetas/L, após ativação total de plaquetas seria liberado de 1 a $3 \mu \mathrm{M}$ de polifosfatos (Ruiz et al., 
2004; Muller et al., 2009). No plasma, o polyP tem meia-vida curta, de cerca de 90 minutos, devido à ação de fosfatases plasmáticas que degradam os polifosfatos (Lorenz et al., 1997; Smith et al., 2006).

O polyP pode iniciar a via intrínseca da coagulação ativando o fator XII e a précalicreína plasmática, que por sua vez, ativa o sistema calicreína-cinina, produzindo altos níveis de bradicinina, que aumenta a permeabilidade vascular e a resposta inflamatória (Muller et al., 2009). Assim como outros ativadores da via de contato, o polyP é um polímero aniônico, que atua como uma superfície carregada negativamente, análoga à superfície de vidro, na qual o fator XII é ativado in vitro.

$\mathrm{O}$ fator $\mathrm{V}$ atua como cofator para a ativação da protrombina em trombina. $\mathrm{O}$ polyP acelera a conversão proteolítica do fator $\mathrm{V}$ em Va, resultando na formação mais rápida do complexo protrombinase (fator $\mathrm{Xa} /$ fator $\mathrm{Va}$ ), acelerando a geração de trombina (Smith et al., 2006). In vitro, a adição de polyP ao plasma juntamente com os reagentes para ativação, como o fator tissular ou mesmo o fator $\mathrm{Xa}$, anula a função anticoagulante do inibidor do fator tissular plasmático (TFPI) (Smith et al., 2006). O TFPI é um inibidor de serinoprotease, que inibe o fator $\mathrm{Xa}$ e o complexo fator tissular/fator VIIa.

A trombina converte o fibrinogênio em monômeros de fibrina que se associam, formando o coágulo tridimensional. Conforme já observado em microscopia eletrônica e por testes de turbidez, o fibrinogênio incubado com polyP e trombina resulta em coágulos de fibrina mais turvos e o polyP também é incorporado às fibras da fibrina, sendo responsável pelo aumento da espessura dessas fibras, tornando os coágulos de fibrina mais resistentes à fibrinólise por efeito independente da atividade do fator XIII (Smith e Morrissey, 2008). Além disso, o polyP retarda a fibrinólise, aumentando a ação do inibidor da fibrinólise ativado pela trombina (TAFI) (Smith et al., 2006) e também inibindo a ligação da fibrina ao ativador de plasminogênio do tipo tissular (t-PA) (Mutch et al., 2010).

A trombina ativa o fator XI por retroalimentação dependente de poliânions. O polyP acelera a ativação do fator XI tanto pela trombina como pela auto ativação do fator XIa, explicando como o fator XI pode atuar na hemostasia normal independente de fator XII (Mutch et al., 2010). 
Juntos, esses estudos mostram que o polyP secretado pelas plaquetas é um potente agente regulador hemostático, que pode agir sobre diferentes pontos da cascata de coagulação (Lorenz et al., 1997; Smith et al., 2006).

\subsection{Hemostasia Comparada}

A participação de células no mecanismo hemostático tem sido observada desde invertebrados. Os limulídeos apresentam amebócitos com grânulos contendo proteínas coagulantes. Ao entrar em contato com uma superfície ativadora, os amebócitos liberam essas proteínas para o fluido circulante, formando um coágulo insolúvel. Os crustáceos apresentam hemócitos, que liberam enzimas que convertem proteínas coaguláveis, presentes no "plasma" em sua forma insolúvel. Em peixes, anfíbios, répteis e aves são encontrados os trombócitos e nos mamíferos as plaquetas (Iwanaga, 1993).

Enquanto as plaquetas, encontradas no sangue circulante de mamíferos, são partículas citoplasmáticas originárias de megacariócitos, as células envolvidas na hemostasia e coagulação sanguínea, em todas as outras espécies de animais não mamíferos, são nucleadas e denominadas de trombócitos (Levin, 2007). Os trombócitos de répteis, bem como de outros vertebrados não mamíferos, apresentam algumas características morfofisiológicas semelhantes às das plaquetas no sistema hemostático, porém são raros os conhecimentos sobre a fisiologia dos trombócitos de répteis (Levin, 2007).

O mecanismo da coagulação sanguínea desde os peixes amandibulados até mamíferos mostra que além da participação de células, a coagulação é mediada por proteínas coaguláveis (Doolittle e Surgenor, 1962).

Os componentes sanguíneos envolvidos na hemostasia começaram a evoluir para sistemas mais complexos há cerca de 450 milhões de anos. Assim, a coagulação sanguínea segue o mesmo padrão fundamental em todos os vertebrados, desde os peixes amandibulados até mamífero (Doolittle e Surgenor, 1962).

Os peixes amandibulados apresentam um sistema de coagulação primitivo, envolvendo fator tissular, protrombina e fibrinogênio (Davidson, Tuddenham e Mcvey, 2003). Análises de sequências de cDNA confirmam a presença de protrombina em mamíferos, aves, répteis, anfíbios e peixes (Banfield e Macgillivray, 1992). Todos os 
vertebrados possuem fibrinogênio, sendo composto por três pares de cadeias polipeptídicas (Doolittle, 1973; 1983). Evidências para a presença dos fatores V, VII, VIII, IX e X em vertebrados não mamíferos são limitadas (Davidson, Tuddenham e Mcvey, 2003). Algumas espécies de peixes, aves e cetáceos não apresentam atividade do fator XII. Por outro lado, estudos da coagulação sanguínea de peixes Danio rerio sugerem a presença das vias de coagulação e anticoagulação muito similar às vias dos humanos (Jagadeeswaran e Sheehan, 1999).

Estudos sobre a hemostasia de répteis demonstraram que algumas espécies de tartarugas marinhas, iguanas, lagartos e serpentes apresentam prolongamento no tempo de coagulação em relação ao de mamíferos, indicando diferenças no mecanismo da coagulação. Esse prolongamento pode ser devido às baixas concentrações ou ausência de alguns fatores da coagulação bem como à presença de anticoagulantes naturais, como o descrito no sangue do lagarto Trachydosaurus rugosus rugosus (Hackett e Hann, 1967). Os répteis de modo geral parecem apresentar os fatores V, VIII, protrombina, fator tissular e fibrinogênio. Por outro lado, o fator XII tem sido detectado em algumas espécies de serpentes como Python molurus bivittatus, Waglerophis merremii e Crotalus durissus terrificus enquanto que outras espécies como Bothrops jararaca, $B$. moojeni e Oxyrophus trigeminus não apresentam esse fator (Nahas et al., 1981; Ratnoff et al., 1990; Prezoto et al., 1991). Essa variação do sistema hemostático no grupo de vertebrados não mamíferos ainda é muito pouco compreendida, principalmente porque são raros os estudos realizados, principalmente no grupo das serpentes. 
OBJETIVOS 


\section{Objetivos}

O objetivo deste trabalho foi investigar o mecanismo hemostático do sangue da serpente Crotalus durissus terrificus, comparando com o de outros animais descritos na literatura, avaliando:

- a presença e a participação dos fatores plasmáticos da coagulação;

- a função e participação dos trombócitos na hemostasia;

- a participação dos polifosfatos no mecanismo hemostático.

Este estudo poderá contribuir na elucidação de alguns aspectos do mecanismo hemostático variado em serpentes, principalmente do sistema intrínseco e a participação dos trombócitos que são pouco estudados em vertebrados não mamíferos. 
MATERIAIS E MÉTODOS 


\section{Materiais e Métodos}

\subsection{Materiais}

\subsubsection{Animais}

Foram utilizadas 18 serpentes Crotalus durissus terrificus (C.d. terrificus) adultas, aparentemente saudáveis e recém-chegadas da natureza, fornecidas pelo Laboratório de Herpetologia do Instituto Butantan e posteriormente pela Recepção de Animais do Laboratório Especial de Coleções Zoológicas. Os experimentos foram aprovados pela Comissão de Ética no Uso de Animais do Instituto Butantan (nº 788/11).

\subsection{Métodos}

\subsubsection{Coleta e amostras de sangue}

As serpentes foram anestesiadas com tiopental sódico $(30 \mathrm{mg} / \mathrm{Kg}$ ) (Chudzinski, Seelaender e Kelen, 1989) e a artéria aorta foi exposta por laparotomia. O sangue foi coletado através de punção da artéria aorta (região próxima ao fígado). Uma parte do sangue foi adicionada ao citrato de sódio 3,8 \%, na proporção de 9:1, para testes de coagulação e de trombócitos, e outra ao EDTA $10 \%(10 \mu \mathrm{L} / \mathrm{mL}$ de sangue $)$ para dados hematológicos e hemograma.

O plasma foi obtido através de centrifugação do sangue citratado a $1800 \mathrm{~g}$ por 15 minutos a $20^{\circ} \mathrm{C}$, sendo mantido a $-80^{\circ} \mathrm{C}$ até o momento do uso. Para obtenção do plasma rico em trombócitos (PRT), o sangue citratado foi mantido em repouso por 2 horas em temperatura ambiente para sedimentação.

\subsubsection{Tromboplastina}

O preparo da tromboplastina foi feito de acordo com Campbell (1954), com algumas modificações. A artéria aorta foi cuidadosamente retirada da serpente e lavada com $\mathrm{NaCl}$ 0,75\% para retirar sangue e eventuais coágulos. Em seguida, foi macerada em solução salina $0,75 \%$ (30 mg de aorta/1 mL de $\mathrm{NaCl} 0,75 \%$ ). A solução foi separada em alíquotas e mantida $\mathrm{a}-80^{\circ} \mathrm{C}$ até o momento de uso. 


\subsubsection{Parâmetros hematológicos}

\subsubsection{Contagem global de eritrócitos, leucócitos e trombócitos}

A contagem global de eritrócitos, leucócitos e trombócitos foi realizada manualmente através da diluição de sangue (1/200) em solução Natt e Herrick (1951). Após 20 minutos, foi colocada uma amostra na Câmara de Neubauer para contagem das células em objetiva de 40X no microscópio óptico (BA 300, Motic). A área de contagem de eritrócitos foi de $2 \mathrm{~mm}^{2}$ e a de leucócitos e trombócitos de $4 \mathrm{~mm}^{2}$.

\subsubsection{Determinação do Hematócrito}

Foi utilizada a "International microcapilary centrifuge", modelo MB (Fanem) através da centrifugação de sangue total anticoagulado com EDTA em tubo capilar por 5 minutos a $12000 \mathrm{~g}$.

\subsubsection{Dosagem de Hemoglobina}

A dosagem de hemoglobina foi realizada utilizando método colorimétrico da cianometahemoglobina, de acordo com as instruções do fabricante (Bioclin). Assim, 10 $\mu \mathrm{L}$ de sangue com anticoagulante EDTA foram adicionados a $2,5 \mathrm{~mL}$ de reativo de Drabkin (ferricianeto de potássio $0,607 \mathrm{mM}$, cianeto de potássio $0,768 \mathrm{mM}$, fosfato de potássio dihidrogênio 1,029 mM e Triton X-100 1mL/L, pH 7,4) (Biggs e Bain, 2011). A leitura foi feita a $540 \mathrm{~nm}$ em espectrofotômetro (Ultrospec 2100, GE Healthcare) e comparada à do padrão de hemoglobina (Bioclin).

Foram utilizados os seguintes cálculos para determinar o valor de hemoglobina em g/dL:

Fator de calibração = concentração do padrão/absorbância do padrão

Hemoglobina $(\mathrm{g} / \mathrm{dL})=$ absorbância do sangue de C.d. terrificus x Fator de calibração 


\subsubsection{Cálculo dos índices hematimétricos}

Os índices hematimétricos avaliam características dos eritrócitos quanto ao volume e ao conteúdo de hemoglobina. Utilizando os valores obtidos com a contagem de eritrócitos, dosagem de hemoglobina e hematócrito, é possível calcular o volume corpuscular médio (VCM), hemoglobina corpuscular média (HCM) e a concentração de hemoglobina corpuscular média (CHCM).

$$
\begin{aligned}
& \mathrm{VCM}=\left(\text { hematócrito/n } \mathrm{n}^{\circ} \text { eritrócitos }\right) \times 10(\mathrm{em} \mathrm{fL}) \\
& \mathrm{HCM}=\left(\text { hemoglobina/n }{ }^{\circ} \text { eritrócitos }\right) \times 10(\mathrm{em} \mathrm{pg}) \\
& \mathrm{CHCM}=(\text { hemoglobina/hematócrito }) \times 100(\mathrm{em} \%)
\end{aligned}
$$

\subsubsection{Dosagem do fibrinogênio}

A dosagem foi feita de acordo com o método colorimétrico de Ratnoff e Menzie (1951), que avalia a tirosina liberada da fibrina pela digestão em meio alcalino, através da medida da intensidade da cor.

Resumidamente, em tubos de vidro de centrifugação, foram adicionados vidro moído, solução salina $0,85 \%$ (cloreto de sódio $0,85 \%$ ), trombina bovina (36 U) (SigmaAldrich) e plasma. Após a formação do coágulo (fibrina), os tubos foram centrifugados. O coágulo foi, então, cuidadosamente espremido ao vidro e o sobrenadante desprezado. $\mathrm{O}$ procedimento foi repetido por mais duas vezes. À fibrina, foi adicionado $\mathrm{NaOH} 10 \%$ e os tubos foram aquecidos em banho fervente. Após o resfriamento dos tubos, foram adicionados água destilada, $\mathrm{Na}_{2} \mathrm{CO}_{3} 20 \%$ e reagente fenólico Folin \& Ciocalteu (Sigma-Aldrich). A leitura da absorbância foi feita a $650 \mathrm{~nm}$ em espectrofotômetro (Ultrospec 2100, GE Healthcare) (Biggs e Bain, 2011).

\subsubsection{Testes de coagulação}

Com exceção do Tempo de Coagulação e de Retração do Coágulo, todos os testes foram realizados com plasma citratado em coagulômetro Start ${ }^{\circ}$ (Stago) a $37{ }^{\circ} \mathrm{C}$, em duplicata. Os testes foram feitos de acordo com Denson e Biggs (1972). 


\subsubsection{Tempo de Coagulação (TC)}

O tempo de coagulação mede o tempo necessário para que o sangue sem anticoagulantes forme o coágulo. Esse teste foi feito através da adição de $1 \mathrm{~mL}$ de sangue sem anticoagulante em tubo de vidro $(11 \times 75 \mathrm{~mm})$. Imediatamente após a coleta o tubo foi colocado em banho Maria a $37^{\circ} \mathrm{C}$ e acionado o cronômetro. Em intervalos de 5 minutos, foram feitas leituras inclinando o tubo, fazendo com que o sangue escorresse pela superfície do tubo para verificar o tempo para formação do coágulo.

\subsubsection{Retração do Coágulo}

A retração do coágulo avalia a capacidade funcional dos trombócitos de retrair o coágulo formado. A retração foi medida de acordo com Rosenfeld (1941). O coágulo, formado no item 3.2.5.1, foi descolado da parede do tubo, com auxílio de alça de platina. O tubo foi vedado e mantido a $37^{\circ} \mathrm{C}$ em banho Maria por duas horas. O volume de soro e o volume total (sangue com soro) foram medidos em proveta graduada. A retração do coágulo é representada em porcentagem de soro liberado em relação ao volume total de sangue.

\subsubsection{Tempo de Protrombina (TP)}

O tempo de protrombina avalia a ativação da via extrínseca através da adição de tromboplastina e cálcio ao plasma citratado. Para esse teste, foram adicionados $50 \mu \mathrm{L}$ de plasma de $C . d$. terrificus e $50 \mu \mathrm{L}$ de tromboplastina de $C$.d. terrificus (obtida de acordo com o item 3.2.2), que foram incubados a $37^{\circ} \mathrm{C}$ por um minuto. Em seguida, foram adicionados $50 \mu \mathrm{L}$ de cloreto de cálcio $0,025 \mathrm{M}$ e o tempo de formação do coágulo foi cronometrado.

\subsubsection{Tempo de Recalcificação}

O tempo de recalcificação avalia todo o sistema de coagulação através da adição de íons cálcio ao plasma citratado. Para avaliar esse tempo, $75 \mu \mathrm{L}$ de plasma foram incubados a $37^{\circ} \mathrm{C}$ por um minuto e, em seguida, adicionados $75 \mu \mathrm{L}$ de cloreto de cálcio 0,025 M e o tempo de formação do coágulo foi cronometrado. 


\subsubsection{Tempo de Tromboplastina Parcial Ativada (TTPA)}

O tempo de tromboplastina parcial ativada (TTPA) avalia a via intrínseca. Neste teste, a cefalina, como substituta das plaquetas, e o caolin, como ativador de FXII, são adicionados ao plasma antes da recalcificação. Para esse teste, $50 \mu \mathrm{L}$ de plasma de C.d. terrificus, $50 \mu \mathrm{L}$ de C. K. Prest ${ }^{\circledR}$ (Stago) e $50 \mu \mathrm{L}$ solução salina $0,75 \%$ foram incubados a $37^{\circ} \mathrm{C}$ por três minutos. Em seguida, $500 \mu \mathrm{L}$ de cloreto de cálcio $0,025 \mathrm{M}$ foram adicionados e o tempo de formação do coágulo cronometrado.

\subsubsection{Tempo de Trombina (TT)}

O tempo de trombina mede o tempo necessário para que uma solução de trombina coagule o plasma. A concentração do fibrinogênio e também a presença de inibidores de trombina podem causar interferências na medida deste tempo. Assim, foram incubados $100 \mu \mathrm{L}$ de plasma em banho-maria a $37^{\circ} \mathrm{C}$. Após um minuto, foram adicionados $50 \mu \mathrm{L}$ da trombina bovina (Sigma-Aldrich) 24, 12 e $6 \mathrm{U} / \mathrm{mL}$ e o tempo de formação do coágulo cronometrado.

\subsubsection{Tromboelastometria}

O tromboelastômetro Rotem ${ }^{\circledR}$ (Rotation Tromboelastogram analyser, Tem Innovations $\mathrm{GmbH}$ ) pode fornecer informações sobre a cinética da hemostasia desde o tempo de coagulação até a formação e estabilidade do coágulo, avaliando as interações entre fatores de coagulação, inibidores e componentes celulares durante as fases de coagulação.

Os seguintes parâmetros foram analisados (Figura 10): tempo de coagulação (TC, em segundos), que corresponde ao início da medição até o começo da formação do coágulo; tempo de formação do coágulo (TFC, em segundos), que é o tempo do início da formação do coágulo até a amplitude de $20 \mathrm{~mm}$; ângulo $\alpha\left(^{\circ}\right)$, que é dado pelo ângulo entre a linha central e a tangente à curva com o ponto de amplitude de $2 \mathrm{~mm}$, que indica a cinética da formação do coágulo; e firmeza máxima do coágulo (FMC, em mm) como a tensão máxima do coágulo (Lang et al., 2005). 


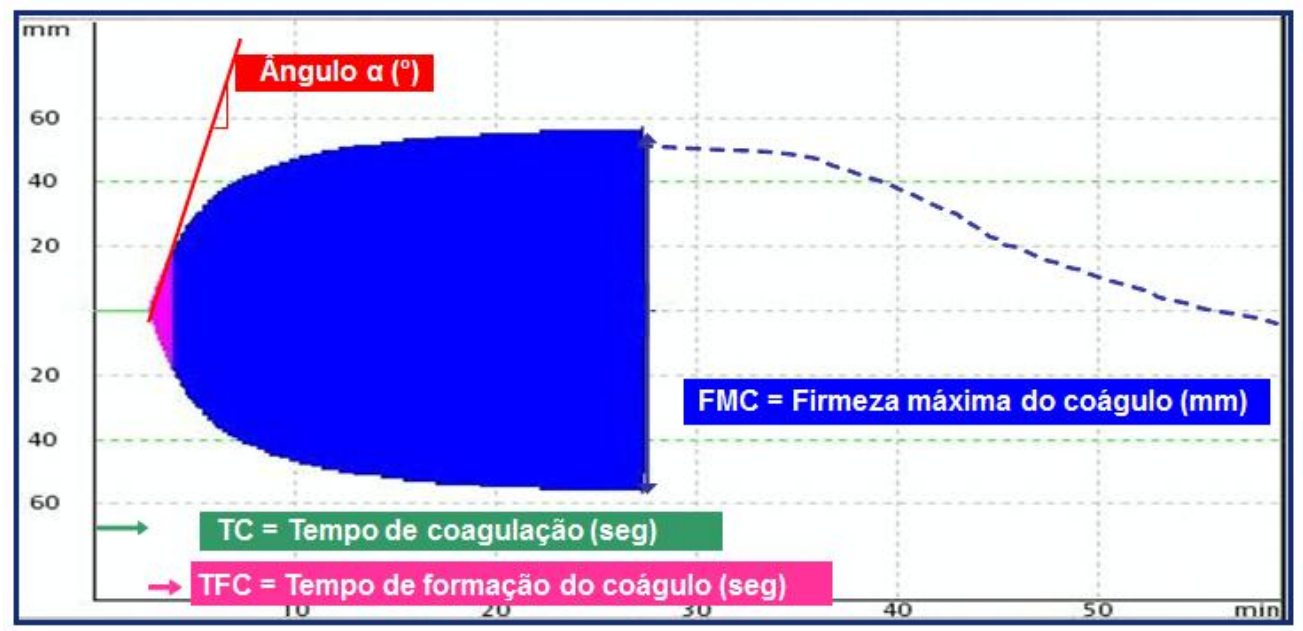

Figura 10. Parâmetros primários da tromboelastometria (Lang et al., 2005).

\subsubsection{Natem}

O teste NATEM avalia a formação do coágulo em sangue total sem anticoagulante. Para esse teste, foram utilizados $300 \mu \mathrm{L}$ de sangue total sem anticoagulante e $40 \mu \mathrm{L}$ de solução salina $0,75 \%$.

\subsubsection{Extem}

O teste EXTEM avalia a formação do coágulo através da ativação da via extrínseca. Para esse teste, foram utilizados $300 \mu \mathrm{L}$ de sangue total citratado, $20 \mu \mathrm{L}$ de tromboplastina de C.d. terrificus, obtida de acordo com o item 3.2.2 (substituindo o reagente ex-tem ${ }^{\circledR}$, composto de fator tissular e fosfolipídeos) (Tem Innovations $\mathrm{GmbH}$ ) e $20 \mu \mathrm{L}$ de cloreto de cálcio 0,2 M.

\subsubsection{Intem}

O teste INTEM avalia a formação do coágulo através da ativação da via intrínseca. Para esse teste, foram utilizados $300 \mu \mathrm{L}$ de sangue total citratado, $20 \mu \mathrm{L}$ de reagente in-tem ${ }^{\circledR}$ (ácido elágico e cefalina de coelho) (Tem Innovations GmbH) e $20 \mu \mathrm{L}$ de cloreto de cálcio 0,2 M. 


\subsection{Intem com Polifosfato}

Para ativação da via intrínseca foi utilizado polifosfato comercial de 45 unidades de fosfato (Sigma-Aldrich). Assim, foram utilizados $300 \mu \mathrm{L}$ de sangue total citratado, $20 \mu \mathrm{L}$ de $\mathrm{P}_{45}(0,17 \mathrm{mg} / \mathrm{mL})$ e $20 \mu \mathrm{L}$ de cloreto de cálcio 0,2 M. Como controle, foram utilizados $300 \mu \mathrm{L}$ de sangue total citratado, $20 \mu \mathrm{L}$ de solução salina $0,75 \%$ e $20 \mu \mathrm{L}$ de cloreto de cálcio $0,2 \mathrm{M}$ ou $300 \mu \mathrm{L}$ de sangue total citratado, $20 \mu \mathrm{L}$ de reagente in-tem ${ }^{\circledR}$, $20 \mu \mathrm{L}$ de $\mathrm{P}_{45}(0,17 \mathrm{mg} / \mathrm{mL})$ e $20 \mu \mathrm{L}$ de cloreto de cálcio $0,2 \mathrm{M}$.

\subsubsection{Fibtem}

O teste FIBTEM analisa especificamente o papel do fibrinogênio na coagulação, estando os trombócitos completamente inibidos. Para este teste, foram utilizados $300 \mu \mathrm{L}$ de sangue total citratado, $20 \mu \mathrm{L}$ de reagente fib-tem® (Tem Innovations $\mathrm{GmbH}$ ) que é composto de citocalasina $\mathrm{D}$, que inibe os trombócitos, e $20 \mu \mathrm{L}$ de tromboplastina de C.d. terrificus.

\subsubsection{Agregação trombocitária}

A agregação plaquetária pode ser avaliada por agregômetro de duas formas diferentes: por impedância usando sangue total citratado e por turbidimetria utilizando plasma enriquecido de plaquetas ou trombócitos.

Os nossos testes de agregação trombocitária foram realizados com sangue total citratado ou plasma rico em trombócitos de C.d. terrificus utilizando agregômetro 560 (Chrono-log () .

Para a agregação trombocitária por impedância, colágeno (concentração final 2,5 $\mu \mathrm{g} / \mathrm{mL}$, Chrono-log) ou ADP (concentração final $50 \mu \mathrm{M}$, Sigma-Aldrich) foram adicionados a $400 \mu \mathrm{L}$ de sangue total e $400 \mu \mathrm{L}$ de solução salina $0,75 \%$, sob agitação constante e a $37^{\circ} \mathrm{C}$, durante 15 minutos.

Para a agregação trombocitária por turbidimetria, $10 \mu \mathrm{L}$ de ionóforo de cálcio (concentração final 0,02 M - Sigma-Aldrich) ou ADP (concentração final $50 \mu \mathrm{M}$, Sigma-Aldrich) foram adicionados a $400 \mu \mathrm{L}$ de plasma rico em trombócitos (PRT). 


\subsubsection{Adesão trombocitária}

A adesão dos trombócitos foi avaliada pelo equipamento ImpactR® (Diamed), de acordo com Varon e Savion (2007). Essse equipamento induz um fluxo laminar com taxa de cisalhamento contínua sobre a superfície inteira da placa de poliestireno coberta pelo cone rotativo. A taxa de cisalhamento, em cada ponto da superfície, é inversamente relacionada à distância do cone da placa e é diretamente relacionada à velocidade angular (Varon e Savion, 2007).

Nesse teste, $130 \mu \mathrm{L}$ de sangue total citratado foram adicionados em placa de poliestireno. Em seguida, foi colocado o cone e submetido a um fluxo de cisalhamento de 1800/s por 2 min. A placa foi lavada com água destilada e a amostra corada com May Grünwald por um minuto. Após a secagem, os trombócitos aderentes e os agregados trombocitários foram observados em um analisador de imagem (Figura 11). Os resultados avaliam a porcentagem de adesão da superfície coberta (SC), o tamanho médio dos objetos corados (por $\left.\mathrm{mm}^{2}, \mathrm{AS}\right)$ e o número de objetos por foto $(\mathrm{Ob})$. 


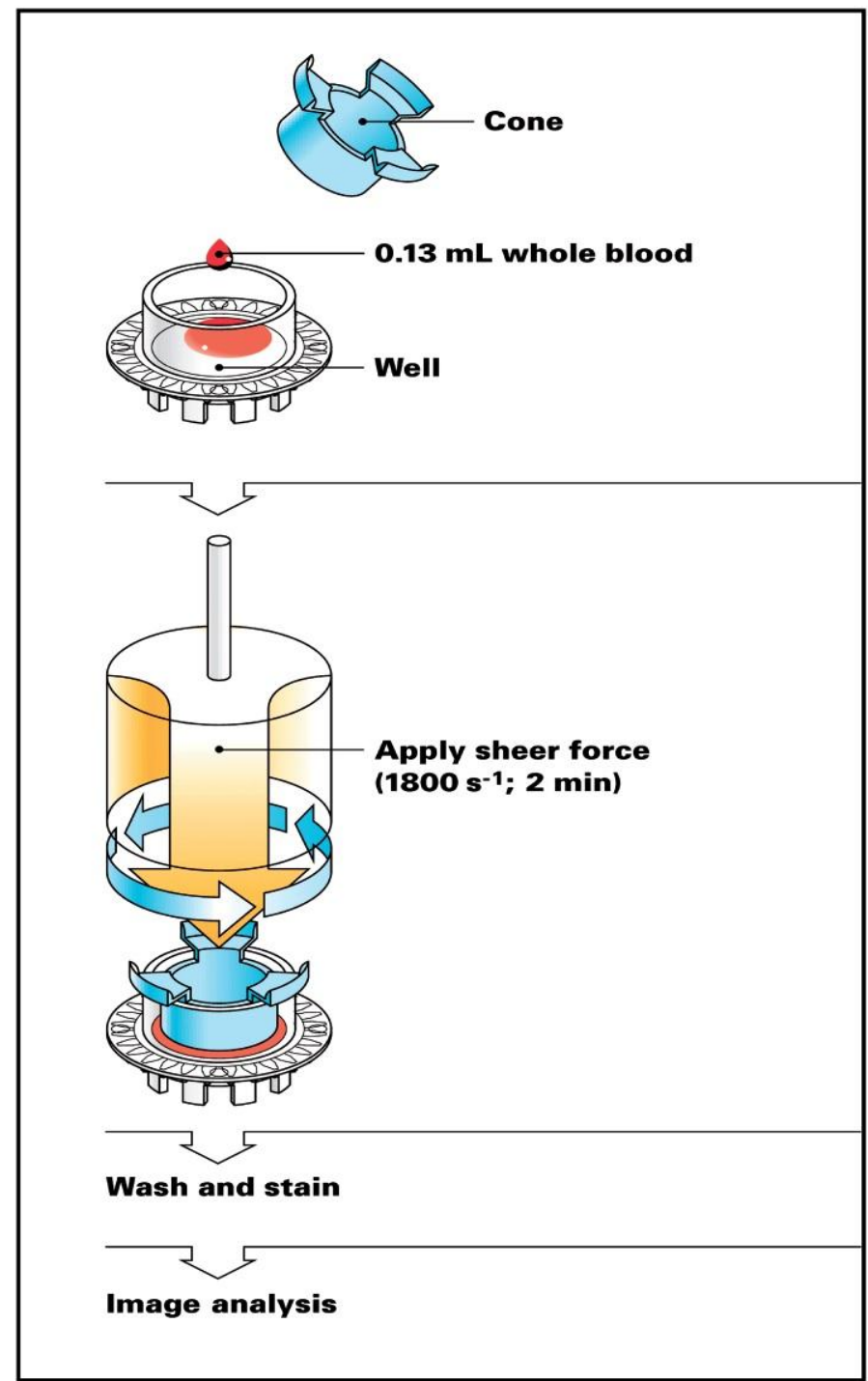

Figura 11. Funcionamento do equipamento ImpactR. A amostra de sangue total citratado é aplicada em placa de poliestireno seguida do cone e, então, submetida ao fluxo de cisalhamento (1800/s) por dois minutos, lavada e corada com May Grünwald. As plaquetas aderentes e os agregados plaquetários são avaliados em um analisador de imagem (Varon e Savion, 2007).

\subsubsection{Microscopia eletrônica de varredura}

\subsubsection{Preparação de plasma rico em trombócitos e trombócitos aderidos}

Cerca de $50 \mu \mathrm{L}$ de PRT, obtido conforme descrito no item 3.2.1, foram colocados em lamínula, que permaneceu em repouso em temperatura ambiente. Após uma hora, foram feitas três lavagens de 5 minutos em tampão Tyrode $(\mathrm{NaCl} 137 \mathrm{mM}, \mathrm{KCl}$ 2,7 $\mathrm{mM}, \mathrm{NaH}_{2} \mathrm{PO}_{4} 3 \mathrm{mM}$, HEPES $10 \mathrm{mM}$, Glicose 5,6 mM, $\mathrm{MgCl}_{2} 1 \mathrm{mM}, \mathrm{CaCl}_{2} \mathrm{mM}, \mathrm{pH}$ $7,4)$. 


\subsubsection{Preparação de agregados trombocitários}

Foram incubados $400 \mu \mathrm{L}$ de PRT com $1 \mu \mathrm{L}$ de colágeno $1 \mathrm{mg} / \mathrm{mL}$ a $37^{\circ} \mathrm{C}$ sob agitação em agregômetro Chronolog. Após 5 minutos, $50 \mu \mathrm{L}$ foram retirados e colocados sobre lamínula.

\subsubsection{Preparação do coágulo de fibrina para estudo da morfologia ultraestrutural da fibrina}

Para obtenção do coágulo, $20 \mu \mathrm{L}$ de plasma humano, de rato e de C.d. terrificus foram incubados com $20 \mu \mathrm{L}$ de trombina bovina $(20 \mathrm{U} / \mathrm{mL}$ para plasma humano e de C.d. terrificus e $40 \mathrm{U} / \mathrm{mL}$ para plasma de rato) em temperatura ambiente. Após 30 minutos, o coágulo foi lavado em tampão Tyrode por três vezes.

O coágulo também foi obtido através da incubação de $20 \mu \mathrm{L}$ de plasma de C.d. terrificus com $20 \mu \mathrm{L}$ de tromboplastina diluída de C.d. terrificus $(20 \mu \mathrm{L}$ de tromboplastina obtida conforme item $3.2 .8,20 \mu \mathrm{L}$ de salina $0,75 \%$ e $2 \mu \mathrm{L}$ de $\mathrm{CaCl}_{2} 0,2$ M).

\subsubsection{Processamento das amostras para microscopia eletrônica de varredura}

O processamento de microscopia eletrônica de varredura foi feito de acordo com Pretorius e col (2006), com algumas modificações. Assim, as amostras obtidas de acordo com os itens 3.2.9.1, 3.2.9.2 e 3.2.9.3 foram fixadas em glutaraldeído 2,5\% por uma hora e depois lavadas em tampão Tyrode por três vezes. Em seguida, as amostras foram pós-fixadas em solução de tetróxido de ósmio $1 \%$ durante uma hora. As amostras foram lavadas em água destilada por três vezes e depois desidratadas em álcool etílico em concentrações de $30 \%, 50 \%, 70 \%, 90 \%$ e $100 \%$ por $5,10,10,15$ e 5 minutos, respectivamente. A secagem foi realizada em aparelho de ponto crítico Leica EM CPD 030. As amostras foram colocadas em bases metálicas de alumínio (stubs) utilizando adesivo de carbono dupla face e cobertas com partículas de ouro com aparelho Sputtering Leica EM SCF 050. As amostras foram observadas em microscópio eletrônico de varredura FEI Quanta 250 utilizando o software xt Microscope Control. 


\subsubsection{Detecção imunológica dos fatores VII e FXII}

\subsubsection{Eletroforese em Gel de Poliacrilamida (SDS-PAGE)}

A eletroforese foi feita em gel de poliacrilamida a $12 \%$ em condições não reduzidas, segundo Laemmli (Laemmli, 1970).

O gel de corrida foi preparado com acrilamida $30 \%$ e bis-acrilamida 0,8\%, água, tampão tris $0,375 \mathrm{M}(\mathrm{pH} 8,8)$, SDS $0,1 \%$, TEMED $0,05 \%$ e persulfato de amônio 0,05 $\%$. O gel de aplicação foi preparado com as mesmas soluções acima, substituindo o tampão tris de $\mathrm{pH}$ 8,8 pelo de $\mathrm{pH}$ 6,8 e adicionando corante vermelho de fenol. Neste gel, foi colocado pente de $1 \mathrm{~mm}$ de espessura contendo dez canaletas para aplicação das amostras. Foi adicionado tampão de amostra (tampão tris 0,05 M pH 6,8, glicerol 10\%, SDS $1 \%$ e azul de bromofenol $0,004 \%$ ) às amostras que foram fervidas em banho seco a $100{ }^{\circ} \mathrm{C}$ por sete minutos e, em seguida, centrifugadas rapidamente.

Foram aplicados $20 \mu \mathrm{g}$ de plasma de C.d. terrificus e $2 \mu \mathrm{g}$ de plasma humano por canaleta, além de $5 \mu \mathrm{L}$ do marcador de massa molecular (Precision Plus Protein Kaleidoscope, BioRad) (de 10 a 250 kD). Como tampão de corrida foi utilizado tris 25 $\mathrm{mM}$, glicina $192 \mathrm{mM}$ e SDS 0,1\%, pH 8,3. A corrida foi feita em amperagem constante de $10 \mathrm{~mA}$ por gel, por aproximadamente uma hora, em aparelho PowerPack HC (BioRad).

\subsubsection{Western Blotting}

O Western Blotting foi feito de acordo com Harlow e Lane (1988). Assim, após a eletroforese (item 3.2.11.1), o gel foi equilibrado por 10 minutos em tampão de transferência (Tris 48 mM, glicina 39 mM, metanol 20\% e SDS 0.037 \%, pH 9.2) a 4 ${ }^{\circ} \mathrm{C}$. As proteínas presentes no gel foram transferidas para membranas de nitrocelulose (Sigma-Aldrich), previamente equilibradas em tampão de transferência, em sistema PowerPack HC (BioRad) por 2 horas a $15 \mathrm{~V}$.

As membranas foram completamente secas em estufa a $37{ }^{\circ} \mathrm{C}$ por 30 minutos e depois umedecidas em água. Para verificar a eficiência da transferência, as membranas foram coradas com Ponceau S 0,2 \% por 10 minutos. As proteínas foram descoradas em solução de lavagem (Tris $10 \mathrm{mM}, \mathrm{NaCl} 150 \mathrm{mM}$, Tween $200,1 \%$, pH 7,5). As 
membranas foram bloqueadas com solução de bloqueio (leite desnatado Molico, Tween $200,01 \%$ e solução de lavagem), a $4{ }^{\circ} \mathrm{C}$.

Após 18 horas, as membranas foram lavadas em solução de lavagem e depois incubadas com anticorpos policlonais humanos anti-fator VII e anti-fator XII produzidos em ovelha ( $10 \mu \mathrm{g} / \mathrm{mL}$ de cada anticorpo, Molecular Innovations) em solução de incubação (gelatina de peixe 0,5\%, Tween 20 0,1\% e solução de lavagem). Após incubação de duas horas em temperatura ambiente, as membranas foram novamente lavadas e o conjugado imunoenzimático anti-ovelha $(0,1 \mu \mathrm{g} / \mathrm{mL}$, Sigma-Aldrich) foi adicionado, incubando por mais duas horas em temperatura ambiente. Após três lavagens com solução de lavagem, foi adicionado o substrato cromógeno DAB, tampão imidazol 0,1 M ( $\mathrm{pH} 7,0), \mathrm{CoCl}_{2} 0,2 \mathrm{M}, \mathrm{H}_{2} \mathrm{O}_{2} 30 \%$ ) até o aparecimento das proteínas reconhecidas pelos anticorpos, sendo a reação interrompida com lavagens sucessivas de água destilada. 
RESULTADOS 


\section{Resultados}

\subsection{Parâmetros hematológicos}

A tabela 1 mostra os resultados da contagem global de eritrócitos, leucócitos e trombócitos, hematócrito, dosagem de hemoglobina, hemoglobina corpuscular média, volume corpuscular médio e concentração de hemoglobina corpuscular média de sangue de C.d. terrificus e também de sangue humano. Podemos observar que os valores diferem muito entre sangue de C.d. terrificus e humano.

Tabela 1. Valores hematológicos e índices hematimétricos médios do sangue da serpente Crotalus durissus terrificus $(\mathrm{n}=17)$.

\begin{tabular}{lll}
\hline & C.d. terrificus $(\bar{X} \pm \mathrm{EP})$ & Homem $^{\mathrm{a}}$ \\
\hline CGE $\left(\times 10^{9} / \mathrm{L}\right)$ & $408,4 \pm 36,42$ & $5000 \pm 500$ \\
CGL $\left(\times 10^{9} / \mathrm{L}\right)$ & $12,47 \pm 1,26$ & $4-10$ \\
CGT $\left(\times 10^{9} / \mathrm{L}\right)$ & $13,37 \pm 1,22$ & $280 \pm 130$ \\
Hematócrito (\%) & $29,5 \pm 1,35$ & $45 \pm 5$ \\
Hemoglobina (g/dL) & $8,19 \pm 0,5$ & $15 \pm 2$ \\
HCM (pg) & $216,96 \pm 16,91$ & $29,5 \pm 2,5$ \\
VCM (fL) & $829,4 \pm 85,85$ & $92 \pm 9$ \\
CHCM (\%) & $27,87 \pm 1,62$ & $33,33 \pm 1,5$ \\
\hline
\end{tabular}

CGE (contagem global de eritrócitos), CGL (contagem global de leucócitos), CGT (contagem global de trombócitos), HCM (hemoglobina corpuscular média), VCM (volume corpuscular médio) e CHCM (concentração de hemoglobina corpuscular média). $\bar{X}$ (média); EP (erro padrão). ${ }^{a}$ (Dacie e Lewis, 1991).

\subsection{Testes de coagulação}

Os valores médios dos parâmetros de coagulação do sangue da serpente $C . d$. terrificus e de sangue humano podem ser observados na tabela 2.

O tempo de coagulação (TC) em humanos varia de 3 a 6 minutos. O tempo observado em C.d.terrificus foi bem mais prolongado, 61 minutos, em média. A retração do coágulo observada em C.d.terrificus, 47,79 \% em média, é muito próxima da observada em humanos (42 a 63 \%) (Thomson, 1970). O tempo de protrombina (TP) 
e o tempo de tromboplastina parcial ativada (TTPA) foram de 56,73 segundos e de 212 segundos, respectivamente, sendo mais prolongados que os de sangue humano, 11 a 16 segundos e 30 a 40 segundos, respectivamente (Dacie e Lewis, 1991). O tempo de recalcificação do plasma de C.d.terrificus foi superior a 10 minutos, sendo muito mais prolongado que o humano, que varia de 80 a 250 segundos (Denson e Biggs, 1972).

Na serpente C.d.terrificus, a concentração de fibrinogênio plasmático observada foi de cerca de $230 \mathrm{mg} / \mathrm{dL}$, valor similar ao observado em sangue humano, que varia de 150 a 400 mg/dL (Dacie e Lewis, 1991).

Tabela 2. Valores médios dos parâmetros de coagulação realizados em sangue da serpente Crotalus durissus terrificus.

\begin{tabular}{llll}
\hline Parâmetros & $\begin{array}{l}\text { C.d.terrificus } \\
(\bar{X} \pm \mathrm{EP})\end{array}$ & $\mathrm{N}$ & Homem \\
& $61,63 \pm 13,45$ & 16 & $3-6^{\mathrm{a}}$ \\
\hline TC (min) & $47,79 \pm 3,56$ & 9 & $42-63^{\mathrm{b}}$ \\
Retração do coágulo (\%) & $56,73 \pm 6,64$ & 9 & $11-16^{\mathrm{c}}$ \\
TP (s) & $212,34 \pm 80,61$ & 9 & $30-40^{\mathrm{c}}$ \\
TTPA (s) & $>600$ & 6 & $80-250^{\mathrm{d}}$ \\
Tempo de recalcificação (s) & $227,47 \pm 20,38$ & 16 & $150-400^{\mathrm{c}}$ \\
Fibrinogênio (mg/dL) & & & \\
\hline
\end{tabular}

TC (tempo de coagulação), TP (tempo de protrombina), TTPA (tempo de tromboplastina parcial ativada) e TT (tempo de trombina); N (número de animais); $\bar{X}$ (média); EP (erro padrão); seg (segundos). ${ }^{\mathrm{a}}$ (Biggs, 1972), ${ }^{\mathrm{b}}$ (Thomson, 1970), ${ }^{\mathrm{c}}$ (Dacie e Lewis, 1991) e ${ }^{\mathrm{d}}$ (Denson e Biggs, 1972).

\subsubsection{Tempo de trombina}

A tabela 3 mostra o tempo de trombina em sangue de C.d. terrificus com diferentes concentrações de trombina. A concentração de trombina comumente utilizada nesse teste com plasma humano é de $6 \mathrm{U} / \mathrm{mL}$, cujo tempo de coagulação é de 13 a 15 segundos (Dacie e Lewis, 1991). Nessa concentração, o tempo observado em plasma de C.d. terrificus foi de cerca de 120 segundos. Com o aumento de 4 vezes a concentração de trombina $(24 \mathrm{U} / \mathrm{mL})$, o tempo observado com plasma de C.d. terrificus foi de cerca de 30 segundos. 
Tabela 3. Valores médios dos tempos de trombina (TT) em plasma de Crotalus durissus terrificus, em segundos $(n=9)$.

\begin{tabular}{lll}
\hline $\begin{array}{l}\text { Concentração de } \\
\text { trombina }(\mathrm{U} / \mathrm{mL})\end{array}$ & $\begin{array}{l}\text { C.d.terrificus } \\
\text { Média } \pm \mathrm{EP}(\mathrm{s})\end{array}$ & Homem \\
\hline 24 & $30,16 \pm 6,7$ & - \\
12 & $56,2 \pm 13,9$ & - \\
6 & $123,97 \pm 39,9$ & $13-15^{\mathrm{c}}$ \\
\hline
\end{tabular}

${ }^{\mathrm{c}}$ (Dacie e Lewis, 1991)

\subsection{Tromboelastometria}

Os dados de cada gráfico da tromboelastometria foram transmitidos para o Excel (tabela 4). Foram realizados testes NATEM, INTEM, EXTEM e FIBTEM e analisados os seguintes parâmetros em cada teste: tempo de coagulação (TC), tempo de formação do coágulo (TFC), ângulo $\alpha$ e firmeza máxima do coágulo (FMC).

No teste NATEM, podemos observar que o tempo de coagulação (TC) variou de 761 a 5194 segundos. No teste INTEM, o TC variou de 1771 a 2627 segundos. No teste EXTEM, os parâmetros TC e TFC também foram prolongados, de 85 a 902 segundos e 67 a 825 segundos, respectivamente. Apesar disso, a amplitude do gráfico medida através do FMC é grande, de 7 a $87 \mathrm{~mm}$. O teste FIBTEM apresentou FMC normal, de 3 a $61 \mathrm{~mm}$, corroborando com o nível de fibrinogênio circulante (cerca de $230 \mathrm{mg} / \mathrm{dL}$ ).

Como podem ser observados na tabela 4, os parâmetros tempo de formação do coágulo (TFC) e ângulo $\alpha$ não foram determinados em alguns testes. O TFC não foi fornecido em alguns testes porque o gráfico não atingiu $20 \mathrm{~mm}$ de amplitude, que é a medida padronizada do aparelho para sangue humano. Da mesma forma, o ângulo $\alpha$, que é dado pelo ângulo entre a linha central e a tangente à curva com o ponto de amplitude de $2 \mathrm{~mm}$, não foi determinado com o sangue de algumas serpentes por não atingir a amplitude mínima.

Assim, os tempos de coagulação observados com os testes NATEM, INTEM e EXTEM (Tabela 4) estão de acordo com o tempo de coagulação, tempo de tromboplastina parcial ativada e tempo de protrombina (Tabela 2), respectivamente, realizados de forma diferente, porém, o principio dos testes são semelhantes. 
Tabela 4. Parâmetros de coagulação obtido da análise por tromboelastometria em sangue da serpente Crotalus durissus terrificus $(\mathrm{n}=8)$.

\begin{tabular}{lllll}
\hline Teste & TC $(\mathrm{s})$ & TFC $(\mathrm{s})$ & ângulo $\alpha\left(^{\circ}\right)$ & FMC $(\mathrm{mm})$ \\
\hline NATEM & $761-5194$ & Nd-769 & $24-80$ & Nd-37 \\
INTEM & $1771-2627$ & Nd-911 & Nd-44 & Nd-38 \\
EXTEM & $85-902$ & $67-825$ & Nd-76 & $7-87$ \\
FIBTEM & $114-1452$ & Nd-589 & Nd-30 & $3-61$
\end{tabular}

TC (tempo de coagulação), TFC (tempo de formação do coágulo), ângulo $\alpha$ (ângulo alpha) e FMC (firmeza máxima do coágulo); mm (milímetros); $\mathrm{Nd}$, valores não determinados.

A figura 12 ilustra os diferentes gráficos da tromboelastometria do sangue de uma serpente C.d.terrificus.

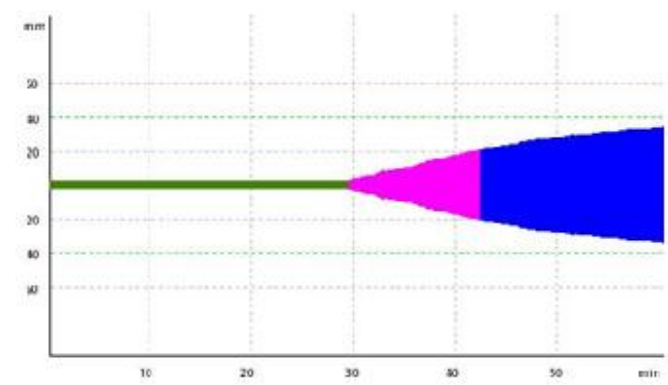

(A)

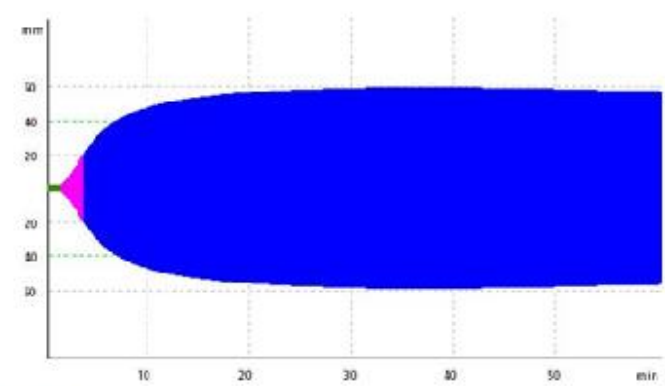

(C)

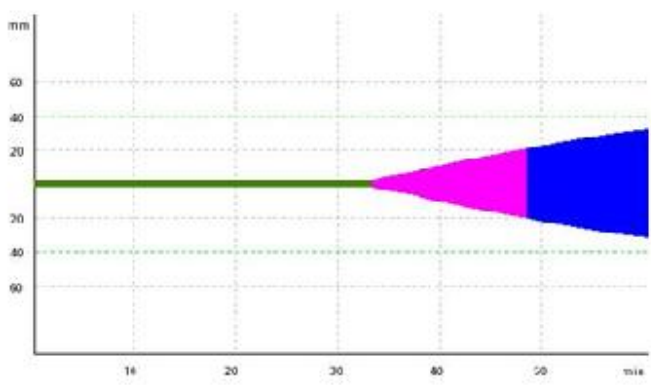

(B)

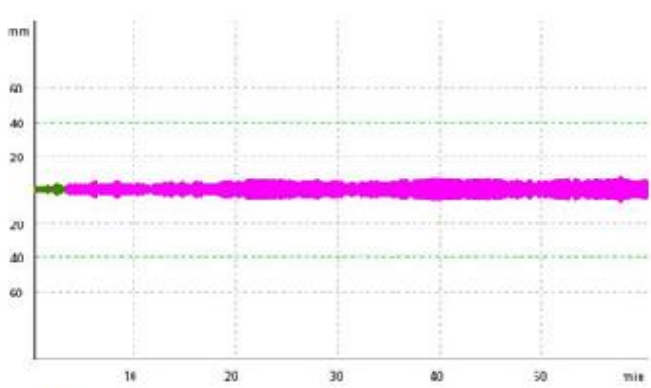

(D)

Figura 12. Representação gráfica de ensaio de tromboelastometria realizado em sangue de uma serpente Crotalus durissus terrificus. A) Em sangue total sem anticoagulante (NATEM). Em sangue citratado, com adição de cloreto de cálcio 0,2 $\mathrm{M}$ e reagentes específicos: B) INTEM (in-tem®); C) EXTEM (tromboplastina de C.d. terrificus) e D) FIBTEM (fib-tem ${ }^{\circledR}$ e tromboplastina de $C$.d. terrificus). Dados captados pelo software ROTEM® no intervalo de tempo de 1 hora. 


\subsubsection{Participação dos polifosfatos na hemostasia}

Para estudar a participação dos polifosfatos na ativação da via intrínseca, o polifosfato comercial de 45 unidades de fosfato $\left(\mathrm{P}_{45}\right)$ foi utilizado como ativador, juntamente com íons cálcio (Figura 13 e tabela 5). Como pode ser observada nas figuras 12A e 12C, a amplitude dos gráficos é bem maior na presença de $\mathrm{P}_{45}$ quando comparada com a dos gráficos na ausência de P45 (Figuras 13B, cálcio e reagente in-tem e D, apenas com cálcio). $\mathrm{O}$ tempo de coagulação (TC) em presença de cálcio e $\mathrm{P}_{45}$ foi de 1657 enquanto que o teste utilizando somente o cálcio apresentou tempo de 2627 segundos, mostrando a participação dos polifosfatos na ativação da via intrínseca.

$\mathbf{A}$

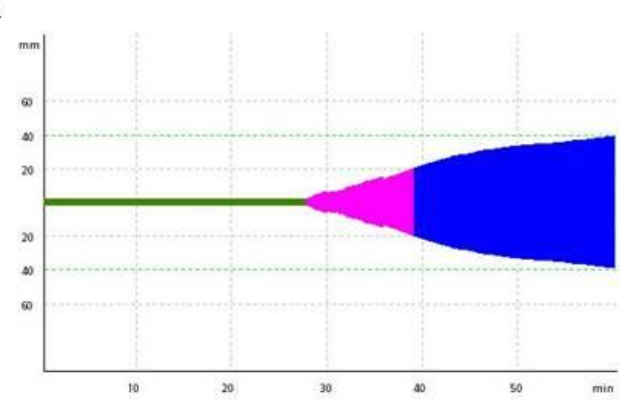

C

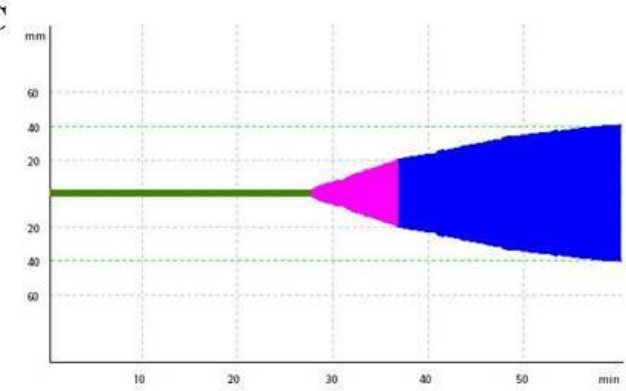

B

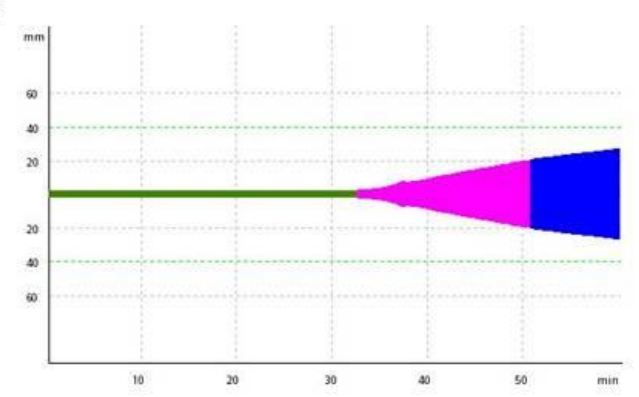

D

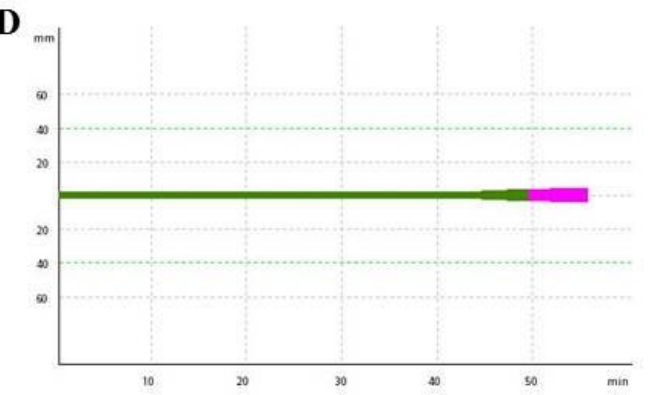

Figura 13. Efeito dos polifosfatos na ativação do sangue de uma serpente Crotalus durissus terrificus. Representação gráfica de ensaio de tromboelastometria realizado em sangue de uma serpente. Em sangue citratado, com adição de cloreto de cálcio 0,2 $\mathrm{M} \mathrm{e}$ reagentes específicos: A) P45 $10 \mu \mathrm{g} / \mathrm{mL}$; B) Reagente in-tem ${ }^{\circledR}$; C) $\mathrm{P}_{45} 10 \mu \mathrm{g} / \mathrm{mL} \mathrm{e}$ reagente in-tem ${ }^{\circledR}$ e D) Recalcificação. Dados captados pelo software ROTEM ${ }^{\circledR}$ no intervalo de tempo de 1 hora. $\mathrm{P}_{45}$ : Sodium phosphate glass (Sigma-Aldrich). 
Tabela 5. Efeitos dos polifosfatos nos parâmetros de coagulação obtidos por tromboelastometria em sangue de uma serpente Crotalus durissus terrificus.

\begin{tabular}{lllll}
\hline Reagentes & TC $(\mathrm{s})$ & TFC $(\mathrm{s})$ & FMC $(\mathrm{mm})$ & ângulo $\alpha\left(^{(}\right)$ \\
& & & & \\
\hline $\mathrm{P}_{45} 10 \mu \mathrm{g} / \mathrm{mL} \mathrm{e} \mathrm{Ca}^{++}$ & 1657 & 678 & 39 & 28 \\
in-tem $\mathrm{e} \mathrm{Ca}^{++}$ & 1944 & 1090 & 27 & 16 \\
$\mathrm{P}_{45}$, in-tem e Ca $^{++}$ & 1650 & 549 & 41 & 32 \\
$\mathrm{Ca}^{++}$ & 2627 & --- & 4 & --- \\
\hline
\end{tabular}

TC (tempo de coagulação), TFC (tempo de formação do coágulo), ângulo $\alpha$ (ângulo alpha) e FMC (firmeza máxima do coágulo); mm (milímetros).

\subsection{Agregação trombocitária}

A agregação trombocitária por impedância foi avaliada através da adição de colágeno $(2,5 \mu \mathrm{g} / \mathrm{mL}$ ) ou ADP (concentração final $50 \mu \mathrm{M}$, Sigma-Aldrich) ao sangue total citratado. Em 10 minutos, a agregação trombocitária em sangue total com colágeno foi de $5,84 \Omega$ (Tabela 6 ).

A agregação trombocitária por turbidimetria foi avaliada pela adição de ionóforo de cálcio $(0,02 \mathrm{M})$ ou $\mathrm{ADP}(50 \mu \mathrm{M})$ ao plasma rico em trombócitos (PRT). Em 10 minutos, a agregação trombocitária em plasma rico em trombócitos (cerca de 11,7 x $10^{9} / \mathrm{L}$ ) com ionóforo de cálcio foi de $24 \%$, em média (Tabela 6 ).

Tabela 6. Parâmetros de agregação trombocitária em sangue total ou PRT da serpente Crotalus durissus terrificus com diferentes agonistas $(\mathrm{n}=5)$. Os dados estão representados como média e erro padrão.

\begin{tabular}{ll}
\hline Agonistas & $\begin{array}{l}\text { C.d. terrificus } \\
(\bar{X} \pm \mathrm{EP})\end{array}$ \\
\hline Ionóforo de cálcio 0,02 M (A23187) $(\%)$ & $24 \pm 3,30$ \\
Colágeno 2,5 $\mu \mathrm{g} / \mathrm{mL}(\Omega)$ & $5,84 \pm 0,85$ \\
ADP 50 $\mu \mathrm{M}(\%)$ & 0 \\
\hline $\mathrm{X}$ (media); EP (erro padrão). &
\end{tabular}

A figura 14 mostra os gráficos da agregação trombocitária de uma serpente $C . d$. terrificus. Nessa serpente, em 10 minutos, o tempo de agregação trombocitária em 
sangue total com colágeno foi de $7 \Omega$ e a agregação em plasma rico em trombócitos com ionóforo de cálcio foi de $23 \%$.

A

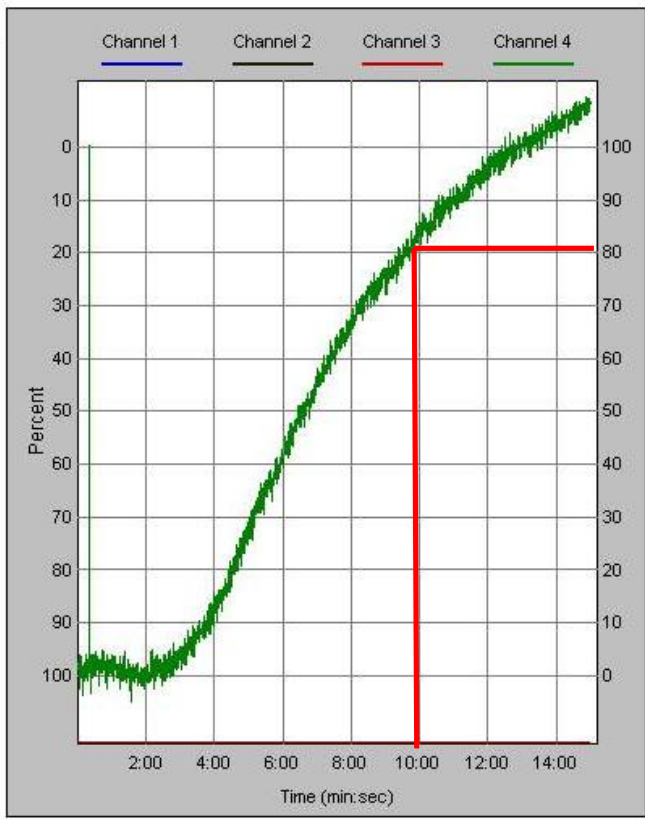

B

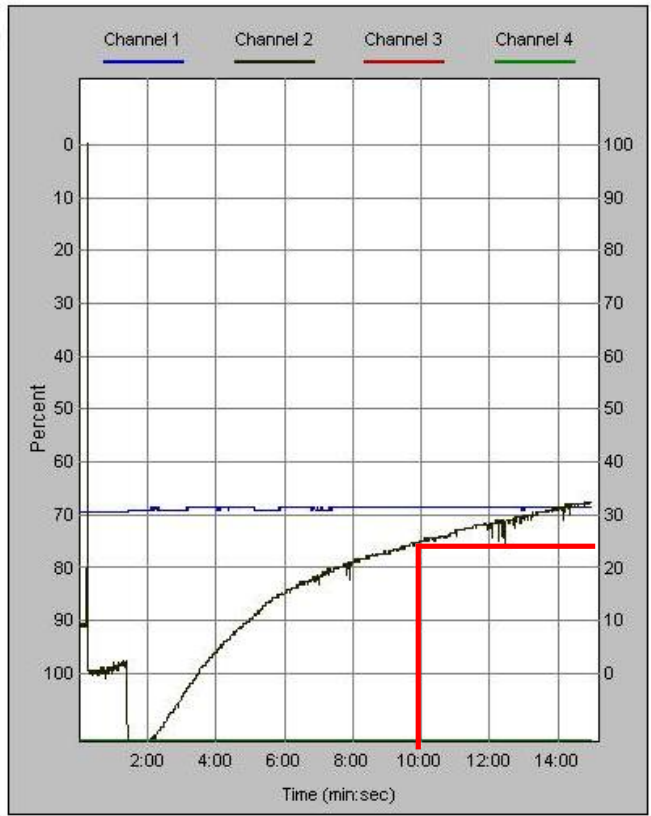

Figura 14. A) Representação gráfica da agregação trombocitária com colágeno 2,5 $\mu \mathrm{g} / \mathrm{mL}$ em sangue total citratado da serpente Crotalus durissus terrificus e em B) da agregação trombocitária com ionóforo de cálcio $0,02 \mathrm{M}$ em plasma rico em trombócito.

A figura 15 mostra que não houve agregação trombocitária induzida por ADP 4,05 $\mathrm{mM}$, em sangue total e em PRT. 

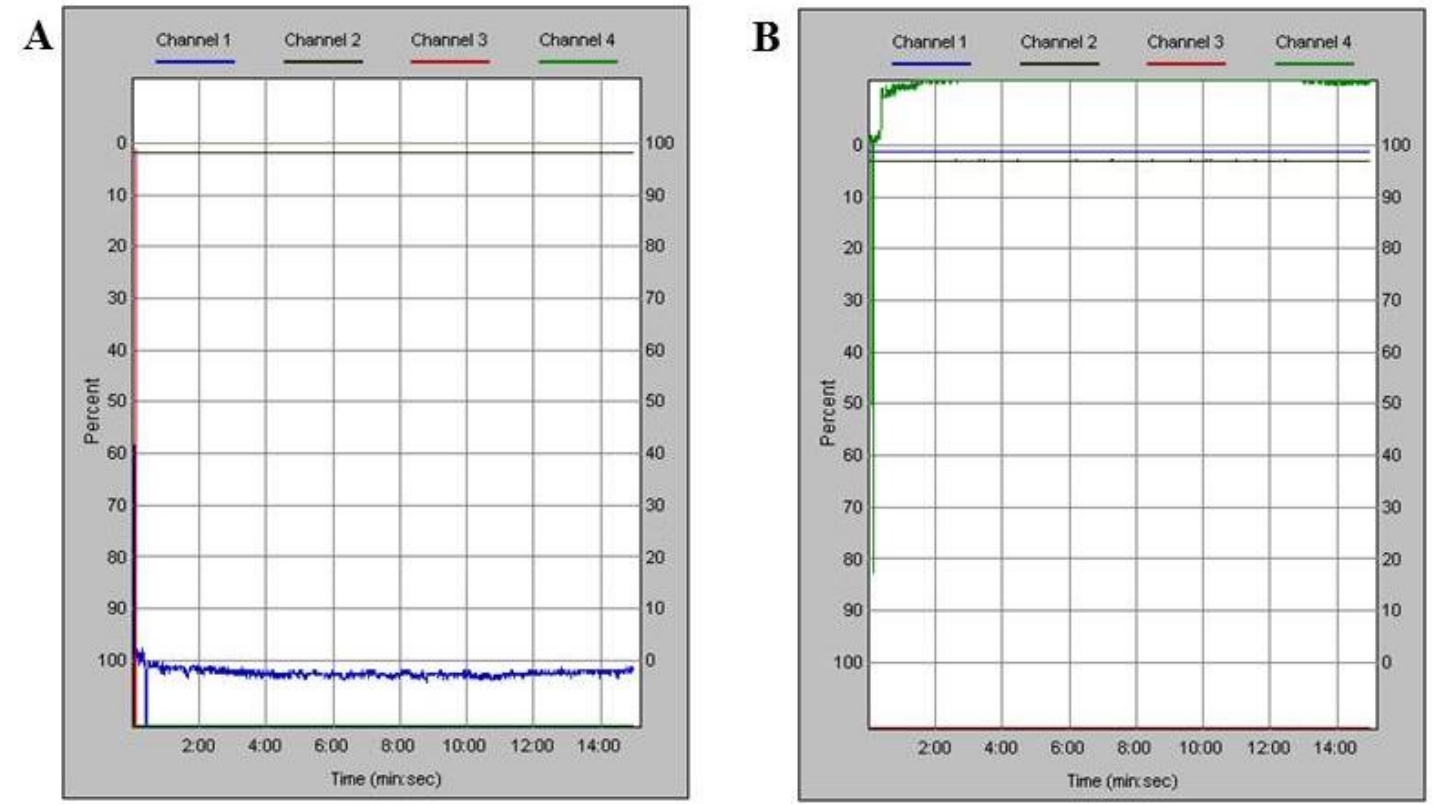

Figura 15. Representação gráfica da agregação trombocitária com ADP $50 \mu \mathrm{M}$ : A) em plasma rico em trombócitos; B) em sangue total citratado da serpente Crotalus durissus terrificus.

\subsection{Adesão trombocitária}

O resultado do teste de adesão trombocitária realizado em ImpactR (Diamed) pode ser observado na figura 16, podendo ser comparado ao resultado em sangue humano. Como podem ser observados na tabela 7 , a porcentagem de superfície coberta de agregados trombocitários (SC) foi de $1,25 \%$, o tamanho médio dos objetos (AS) foi de $35,58 \mu \mathrm{m}^{2}$ e o número de objetos por figura (Obs) foi de 253,2, em média. 
A
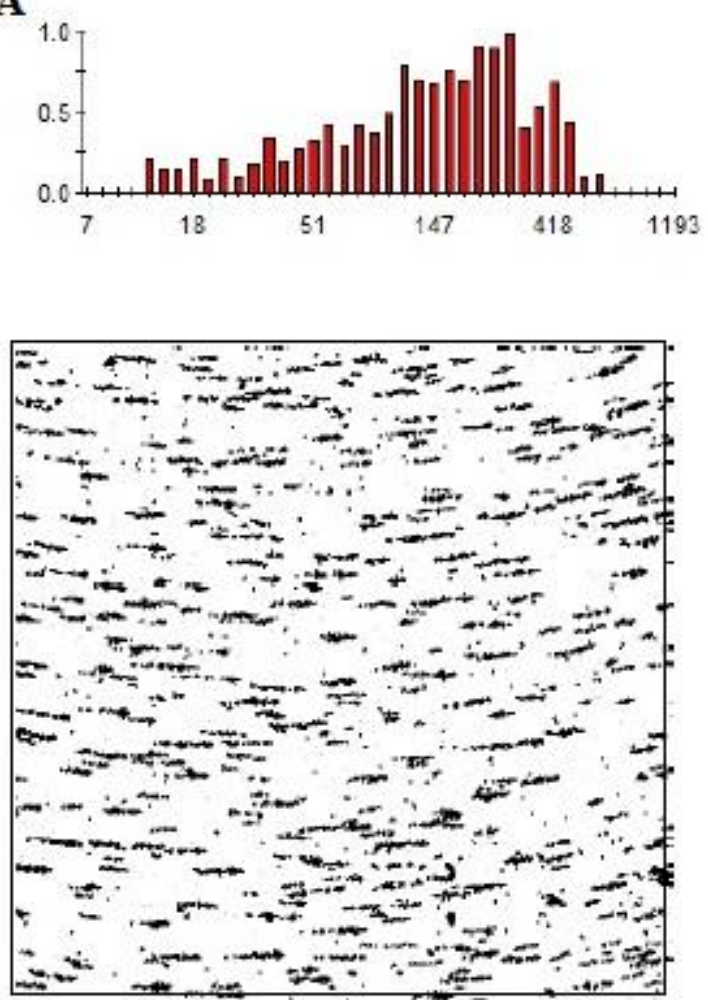

B
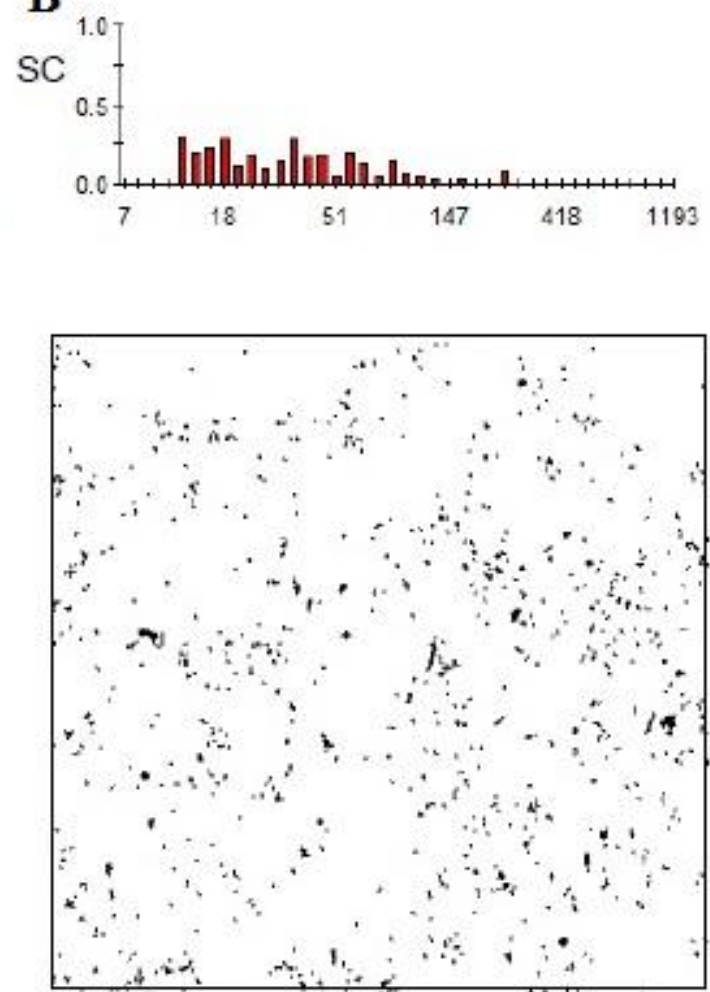

Figura 16. Adesividade trombocitária em ImpactR. A) Resultado representativo de uma amostra de sangue humano normal. B) Resultado representativo de amostra de sangue citratado de uma serpente Crotalus durissus terrificus. SC: Superfície coberta.

Tabela 7. Parâmetros da adesividade trombocitária com sangue da serpente Crotalus durissus terrificus $(\mathrm{n}=5)$. Os dados estão representados como média e erro padrão.

\begin{tabular}{lll}
\hline Parâmetros & C.d.terrificus $(\bar{X} \pm \mathrm{EP})$ & Controle \\
\hline Superfície coberta $(\%)$ & $1,25 \pm 0,37$ & 11 \\
Tamanho médio $\left(\mu \mathrm{m}^{2}\right)$ & $35,58 \pm 5,23$ & 73 \\
Objetos & $253,2 \pm 82,7$ & 903
\end{tabular}

EP (erro padrão). Controle: sangue humano (Diamed). 


\subsection{Detecção imunológica dos fatores VII e FXII}

Os plasmas de C.d.terrificus e humano foram submetidos à eletroforese e Western Blotting. Os resultados podem ser observados na figura 17 para os fatores VII e XII. Podemos notar que o plasma da serpente contém proteínas que reagiram com os anticorpos contra os fatores VII e XII (Figuras 17A e 17B, respectivamente), indicando que os epítopos presentes nessas proteínas reconheceram os anticorpos correspondentes.

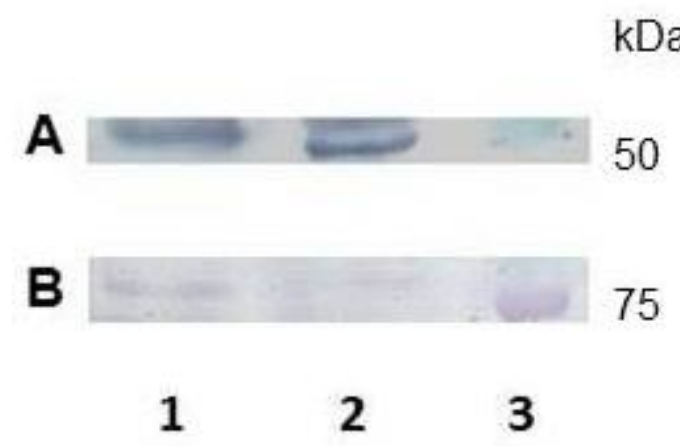

Figura 17. Detecção imunológica comparativa dos fatores plasmáticos FVII e FXII entre plasma de serpente Crotalus durissus terrificus e humano em Western Blotting. As amostras foram aplicadas em gel de poliacrilamida $12 \%$ e transferidas para membrana de nitrocelulose. As membranas foram incubadas com anti-FVII (A) e antiFXII (B). 1) Plasma humano; 2) Plasma de C.d.terrificus; 3) Padrão de massa molecular.

\subsection{Microscopia eletrônica de varredura}

A figura 18 mostra a eletromicrografia de células em plasma rico em trombócitos. Os trombócitos (T) são as células alongadas com superfícies lisas. Podemos observar a presença de vários linfócitos (células arredondadas com protrusões citoplasmáticas) que normalmente contaminam o PRT. Já na figura 19, podemos observar trombócitos aderidos à superfície e iniciando a adesão uns aos outros. É possível observar também a emissão de pseudópodes.

As figuras 20A e 20B mostram as eletromicrografias de fibrinas de C.d.terrificus formada através da incubação de plasma e trombina e de plasma e tromboplastina homóloga, respectivamente. As figuras 20C e 20D mostram as eletromicrografias de fibrinas humana e de rato, respectivamente, formadas através da incubação de plasma e trombina. Podemos observar que a fibrina de C.d. terrificus formada através da 
incubação de plasma e trombina difere da fibrina formada da incubação de plasma e tromboplastina homóloga. As fibras da fibrina formadas com tromboplastina de C.d. terrificus são mais espessas que as demais, embora apresente um maior número de poros. Podemos notar que o arranjo das fibras das fibrinas de rato Wistar e humana difere pouco entre si, mas apresenta diferenças quando comparadas com as fibrinas de C.d. terrificus. 
Figura 18. Microscopia eletrônica de varredura de plasma rico em trombócitos de Crotalus durissus terrificus. Observar a superfície lisa dos trombócitos enquanto que os linfócitos mostram varias projeções citoplasmáticas. T: trombócito; L: leucócito.

Figura 19. Microscopia eletrônica de varredura de trombócito aderido de Crotalus durissus terrificus em superfície de vidro. Observar a formação típica de célula em adesão. 

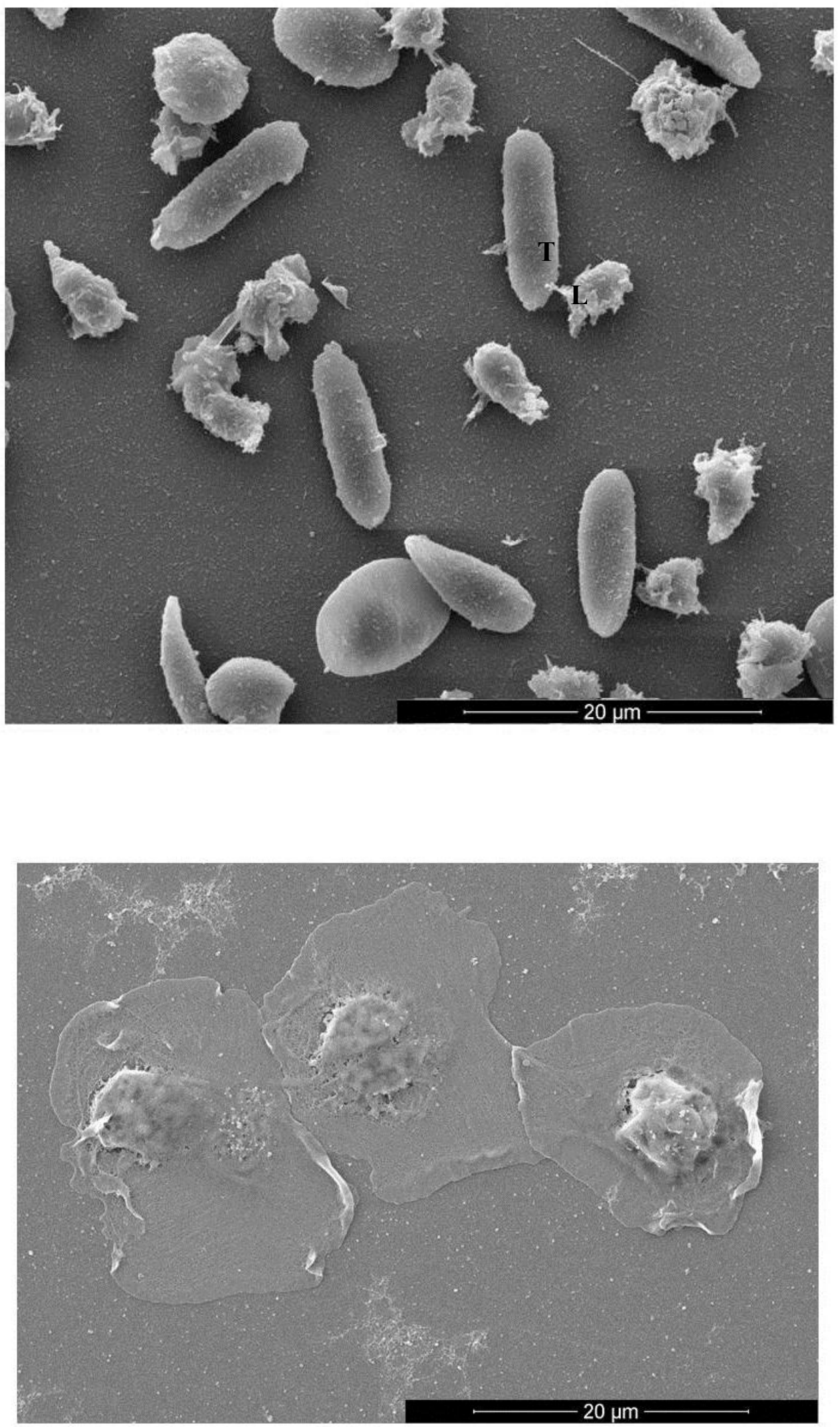
Figura 20. Microscopia eletrônica de varredura de coágulo de fibrina. A) Fibrina de Crotalus durissus terrificus formada através da incubação de plasma e trombina; B) Fibrina de C.d.terrificus formada através da incubação de plasma e tromboplastina; C) Fibrina humana formada através da incubação de plasma e trombina; e d) Fibrina de rato formada através da incubação de plasma e trombina. 

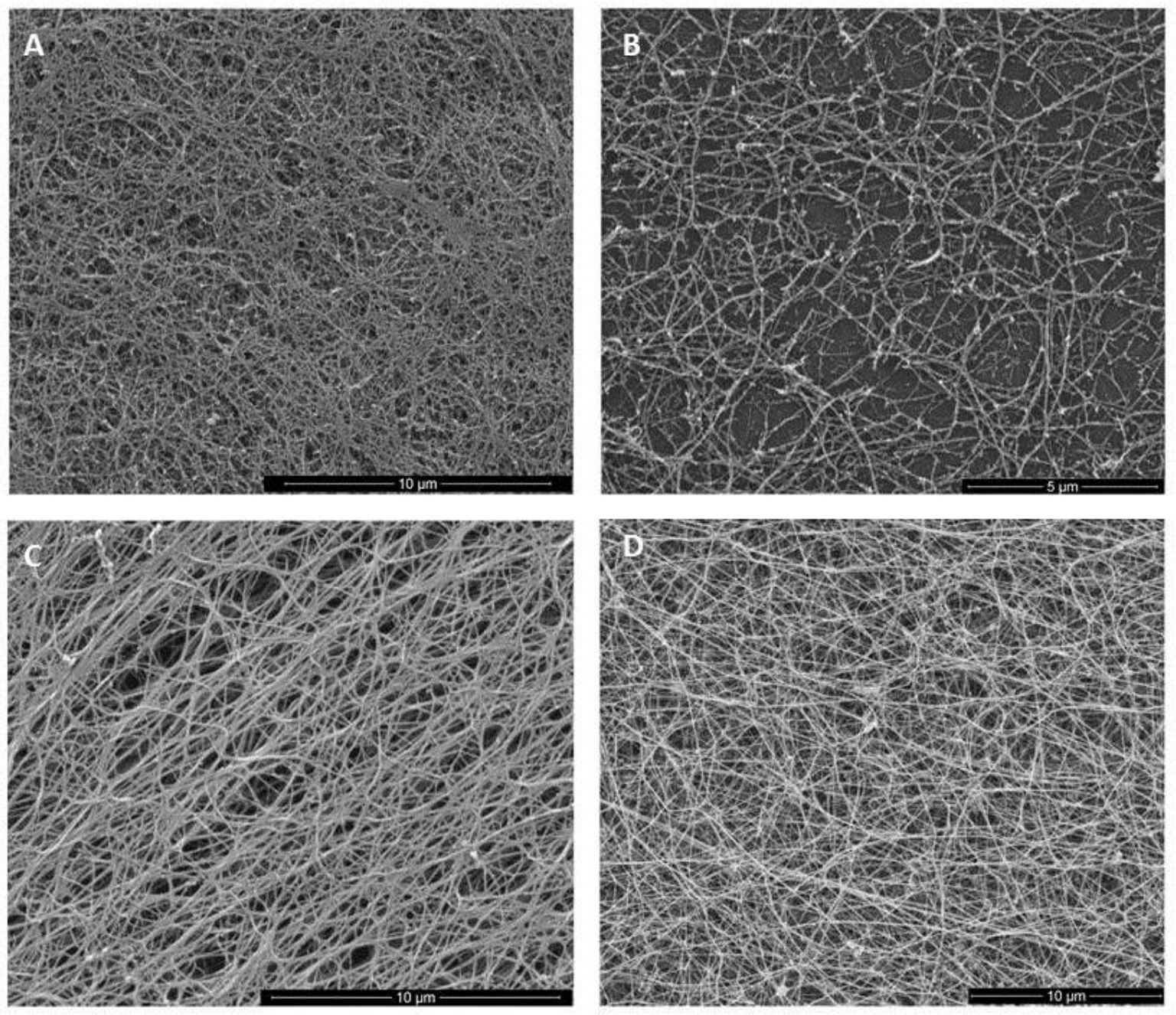
DISCUSSÃO 


\section{Discussão}

Os nossos resultados mostram que o mecanismo hemostático do sangue da serpente Crotalus durissus terrificus é eficiente, e como esperado, apresentam algumas diferenças e similaridades dos mamíferos. Os valores hematológicos e alguns aspectos funcionais da coagulação observados em serpentes C.d. terrificus estão dentro das variações descritas em outras espécies de serpentes, porém apresentaram muitas diferenças dos mamíferos.

Os resultados dos parâmetros hematológicos são semelhantes aos observados em serpentes C.d. terrificus (Santos et al., 2008) e C.d. collilineatus (Motta et al., 2011) e também em outras espécies como Bothrops leucurus (Grego et al., 2006), Ophiophagus hannah (Salakij et al., 2002) e Natrix natrix natrix (Wojtaszek, 1991), mostrando que os nossos exemplares estavam saudáveis, corroborando com os exames físicos dos animais, sem evidências de sintomatologia clínica.

Em mamíferos, a hemostasia ocorre em três etapas sobrepostas: fases de iniciação, amplificação e propagação, com a participação de células carreadoras de fator tissular e plaquetas. As vias extrínseca e intrínseca do modelo de cascata de coagulação tradicional estão relacionadas às fases de iniciação e propagação, respectivamente (Monroe e Hoffman, 2006). Esse modelo de coagulação enfatiza a participação das plaquetas e células carreadoras de fator tissular, além da iniciação pelo fator tissular. Assim, esse modelo também parece ser adequado para explicar o mecanismo hemostático em serpentes. Porém, ainda há alguns questionamentos do verdadeiro papel do sistema de contato da ativação da via intrínseca da coagulação in vivo, uma vez que a deficiência do fator XII, não resulta em distúrbios hemorrágicos (Muller e Renne, 2008).

O tempo médio de coagulação do sangue total observado em serpentes C.d. terrificus foi prolongado em relação ao sangue humano. Nosso resultado é semelhante ao da serpente não peçonhenta Waglerophis merremii, com 31,3 minutos. Porém, o sangue da serpente Bothrops jararaca (B. jararaca) não coagula, mesmo em um período de 24 horas (Nahas et al., 1981), quando o fator tissular não é adicionado. Essa diferença está relacionada com a ausência do fator XII (Nahas et al., 1981) e elevada 
presença de inibidores de trombina no sangue da B. jararaca (Nahas et al., 1973). Porém, é notório que esta serpente consegue estancar a hemorragia após uma lesão vascular.

O teste de tromboplastina parcial ativada avalia o sistema intrínseco. Esse teste também apresenta tempos muito variados entre os répteis. A serpente C.d. terrificus apresentou tempo muito próximo ao de B. jararaca, 319 segundos, em média (Nahas et al., 1981). Por outro lado, a Waglerophis merremii apresentou tempo de coagulação de 47,9 segundos (Nahas et al., 1981), sendo mais próximo ao dos humanos, que varia de 30 a 40 segundos. Em iguanas também foram observados tempos muito prolongados, de 170 segundos, que podem ser devido à presença de inibidores naturais plasmáticos (Kubalek, Mischke e Fehr, 2002). Estes resultados mostram que além da presença ou não dos fatores de contato, o nível dos inibidores plasmáticos tem influenciado a velocidade com que o plasma coagula. Assim, a Waglerophis merremii que possui o sistema de contato e não apresenta grande quantidade do inibidor tipo trombina, apresentou um tempo mais curto que o de B. jararaca e C.d. terrificus que possuem esse inibidor circulante no plasma (De Morais, Grego e Tanaka-Azevedo, 2008).

A espécie-especificidade da tromboplastina é bastante relatada em testes de avaliação da via extrínseca na determinação do tempo de protrombina (Kubalek, Mischke e Fehr, 2002). O uso de tromboplastina heteróloga originária de mamíferos apresenta resultados variáveis e discrepantes em animais não mamíferos, tornando necessária a utilização de reagentes homólogos. Desse modo, utilizamos extrato tissular obtido da maceração da aorta da própria serpente como fonte de tromboplastina tissular homóloga.

O sangue da serpente C.d. terrificus apresentou tempo de protrombina mais próximo ao de tartarugas marinhas que coagulou em torno de 45 segundos (Soslau et $a l ., 2004)$ e da serpente Bitis arientans com tempo mais prolongado de 73 segundos (Frost et al., 1999). Entretanto, a serpente Waglerophis merremii apresenta tempo mais curto de 14,1 segundos, semelhante ao de sangue humano, enquanto que o jacaré Caiman crocodilos (Arocha-Piñango, Gorzula e Ojeda, 1982), a iguana Iguana iguana (Kubalek, Mischke e Fehr, 2002) e a serpente B. jararaca, mesmo com tromboplastina homóloga, apresentaram tempo bastante prolongado (Nahas et al., 1981). O lagarto 
Trachydosaurus rugosus apresentou tempo ainda mais prolongado, 1800 segundos (Hackett e Hann, 1967).

O tempo para formação do coágulo com plasma de C.d. terrificus utilizando a trombina bovina foi maior que o tempo observado com plasma humano. Quando comparado ao tempo averiguado em iguana (Iguana iguana) o tempo de trombina (TT) é ainda mais prolongado, sendo de 266 segundos (Kubalek, Mischke e Fehr, 2002). Com isso, a trombina não mostrou espécie-especificidade, de tal forma que as diferenças da coagulabilidade estão relacionadas principalmente a níveis de antitrombinas presentes no sangue desses animais. Alguns répteis como o lagarto Trachydosaurus rugosus rugosus (Hackett e Hann, 1967; Nahas et al., 1973) e a serpente $B$. jararaca apresentam inibidores de proteases naturais plasmáticos que reduzem a atividade coagulante do sangue (Tanizaki et al., 1991). Tanaka-Azevedo e col (2003) isolaram um inibidor específico da atividade coagulante da trombina (BjI) presente no plasma da serpente $B$. jararaca. Entretanto, este inibidor não bloqueia a ativação da via extrínseca da coagulação nem interfere na agregação plaquetária. O BjI também foi observado nas serpentes B. jararacussu, B. alternatus e C. d. terrificus (De Morais, Grego e Tanaka-Azevedo, 2008).

A tromboelastometria analisa a coagulação em sangue total, fornecendo informações sobre a viscoelasticidade sanguínea incluindo a cinética do início da coagulação e propagação, interação plaqueta/fibrina e fibrinólise. Em medicina veterinária, valores de referência para tromboelastometria têm sido estabelecidos para diferentes animais como cães (Bauer, Eralp e Moritz, 2009), gatos (Alwood et al., 2007), cavalos (Epstein et al., 2009) e porcos (Morey et al., 2010), assim como para animais de laboratório como ratos (Kaspereit, Doerr e Dickneite, 2004), camundongos (Jankun et al., 2010), coelhos (Nielsen, Geary e Baird, 2000) e macacos (Fong, Ha e Hotchkiss, 2012). Os valores dos parâmetros de coagulação nesses animais são semelhantes aos valores de referência para humanos, apresentando similaridades na dinâmica do coágulo entre esses mamíferos. Contudo, não há dados em relação a outras espécies de vertebrados não mamíferos. Portanto, esta é a primeira vez que esses valores de tromboelastometria são estabelecidos para animais de outra classe de vertebrados.

$\mathrm{O}$ estudo tromboelastométrico do sangue da serpente C.d. terrificus demonstrou dificuldades analíticas. Alguns parâmetros não foram mensurados, como ocorre com o 
TFC e $\alpha$ ângulo. Este fato e explicado porque o aparelho foi padronizado para humanos. Comparando os resultados com os de sangue humano, os valores de tempo de coagulação e tempo de formação do coágulo foram aumentados para os testes NATEM e INTEM. No teste EXTEM, foi observado um ligeiro prolongamento do TC e TFC. O teste FIBTEM apresentou valor de FMC normal, semelhante ao do homem, explicado pela concentração do fibrinogênio plasmático que são similares. Esses resultados obtidos com o sangue de C.d. terrificus estão de acordo com os resultados observados nos testes TP, TTPA e TT, que também são prolongados quando comparados com o sangue humano. Vale ressaltar que a diferença importante entre esses testes e os de tromboelastometria é que esses testes são realizados em plasma, na ausência de células sanguíneas, enquanto que a tromboelastometria é realizada em sangue total, na presença de eritrócitos, leucócitos e trombócitos.

Os polifosfatos atuam como uma superfície carregada negativamente, ativando o fator XII e a pré-calicreína plasmática da via intrínseca da coagulação, além de ativar o fator V, acelerando sua ativação pela trombina e fator Xa (Muller et al., 2009). Os répteis de modo geral parecem apresentar o fator $\mathrm{V}$ enquanto que alguns são deficientes em fator XII, que está presente nas serpentes Crotalus durissus (Prezoto et al., 1991). Em nossos estudos para avaliar o efeito do polifosfato no sistema da coagulação do sangue de C.d. terrificus, utilizamos polifosfato de 45 unidades de fosfato, único disponível comercialmente, de cadeia menor que os utilizados na literatura. Quando adicionamos os polifosfatos no teste INTEM (na presença de ácido elágico e cefalina de coelho ou não e de cálcio), o TC foi bastante reduzido quando comparado ao teste INTEM sem polifosfatos. A amplitude do gráfico também aumentou, permitindo o cálculo do TFC e do $\alpha$ ângulo (Smith et al., 2010) confirmando assim a presença de sistema de contato funcional nessa espécie de serpente e também o efeito dos polifosfatos no seu mecanismo hemostático. Estudos mostram que o tamanho da cadeia de polifosfatos influencia na ativação da via de contato, sendo que os de cadeias maiores são mais potentes na ativação, porém em nosso estudo está evidente que mesmo o de cadeia 45 unidades, foi capaz de encurtar o tempo de coagulação.

A detecção imunológica dos fatores VII e XII por Western Blotting mostrou que a serpente C.d. terrificus apresenta ambos os fatores e que eles possuem epítopos em comum com os mesmos fatores humanos. A reação do fator XII com o anticorpo anti- 
FXII foi bem menos intensa que a reação do fator VII. Isso pode ser devido às baixas concentrações desse fator no plasma. Somente esses resultados não podem indicar se esses fatores atuam funcionalmente como os de humano. Contudo, ao analisar os resultados dos testes que avaliam as vias extrínseca e intrínseca da coagulação, fica evidente a participação dos dois fatores, principalmente do fator VII na fase de iniciação da coagulação, juntamente com o fator tissular. A reação cruzada de fatores plasmáticos de répteis com anticorpos contra fatores humanos já foram observadas. Os fatores II e $\mathrm{X}$ de tartarugas marinhas reagiram com os anticorpos humanos correspondentes (Soslau et al., 2004) assim como o fibrinogênio da serpente B. jararaca (Vieira et al., 2008).

A ativação do mecanismo hemostático em serpentes C.d. terrificus parece estar relacionada principalmente à ativação da coagulação pelo fator tissular. Assim, a fase de iniciação parece muito mais eficiente que a fase de propagação, ou seja, a via de contato, embora o fator XII esteja presente nessa espécie. O prolongamento da coagulação pela ativação da via de contato pode ser também devido às baixas concentrações de alguns fatores de coagulação (Nahas et al., 1981). Em uma lesão vascular, onde a camada subendotelial é exposta, a presença do colágeno permitirá a formação do tampão trombocitário e a liberação do fator tissular iniciará a formação do coágulo, consolidando a importância da hemostasia primária, com importante participação dos trombócitos.

Assim, em relação à função dos trombócitos, verificamos que são eficientemente ativados por colágeno, por ionóforo de cálcio e mesmo por trombina (dados não mostrados), pois se aumentarmos a concentração da trombina, os trombócitos agregam, mostrando que há receptores específicos na sua membrana. Assim como descritos em trombócitos de tartarugas e aves, o ADP não induziu agregação nos trombócitos de C.d. terrificus (Stiller, Belamarich e Shepro, 1975; Pellizzon et al., 2002).

$\mathrm{O}$ equipamento ImpactR tem sido descrito como um teste funcional rápido da adesão plaquetária sob fluxo com taxa de cisalhamento contínua sobre a superfície da placa de poliestireno. Nesse teste, a superfície coberta, em média de $1,25 \%$, foi muito inferior à observada com sangue humano, cerca de $11 \%$. A taxa de cisalhamento está relacionada à força aplicada à área, que corresponde à superfície da placa de poliestireno enquanto que a força está diretamente relacionada à massa e à aceleração. Contudo, como o equipamento é padronizado para sangue humano, não podemos alterar 
a massa do cone, apenas a velocidade angular (em rotações por minuto). Possivelmente, a taxa de cisalhamento não esteja representando as condições de fluxo do sangue da serpente. Porém, em termos qualitativos, não há dúvida da capacidade dos trombócitos de C.d. terrificus de aderir à superfície de carga negativa ou à camada subendotelial como pode ser observado na eletromicrografia.

As plaquetas e os níveis de fibrinogênio são importantes no processo da retração do coágulo. $\mathrm{Na}$ serpente C.d. terrificus que apresenta número de trombócitos bem menor que o do humano, mas com concentração de fibrinogênio semelhante, parece apresentar a mesma eficiência fisiológica. Assim, a retração do coágulo observada no sangue da serpente C.d. terrificus está dentro da média observada em sangue humano, de 42 a $63 \%$ (Thomson, 1970).

O fibrinogênio plasmático, na presença de trombina, é transformado em fibrina através de uma proteólise parcial, tornando-se insolúvel. A molécula de fibrinogênio ao longo da escala zoológica mantém algumas similaridades, sendo encontrada em todos os animais vertebrados, desde peixes ciclostomados até mamíferos e, mesmo entre os invertebrados como os crustáceos, é possível observar uma proteína muito similar em tamanho e função (Doolittle, 1983; 1984; Iwanaga, 1993). Equinodermes, como pepinos do mar, e protocordados, como anfioxos, possuem fragmentos relacionados a um ancestral do fibrinogênio (Xu e Doolittle, 1990). Em camarões (Farfantepenaeus paulensis), também foi observada uma proteína coagulante que desempenha papel semelhante ao do fibrinogênio (Perazzolo et al., 2005).

Pretorius e col (2009) classificaram as fibras de acordo com a espessura em três classes: finas, intermediárias e espessas. Assim, os autores observaram que as fibras de macacos, antílopes e equinos não apresentam diferenças significantes entre si, bem como as fibras humanas, ovinas e de pinguins. A única espécie de répteis estudada foi a da tartaruga marinha (Caretta caretta) que apresentou uma distribuição das fibras de fibrina diferente de todos as outras analisadas, sugerindo que essas diferenças possam estar relacionadas com a escala evolucionária. O aspecto morfológico das fibras de fibrina do plasma de C.d. terrificus difere do das fibras de rato e humano, assim como de outras espécies descritas na literatura. Contudo, a determinação da espessura das fibras da fibrina de C.d. terrificus não foi feita ainda porque, para a confiabilidade das medidas, requer um microscópio eletrônico de varredura com maior resolução do que 
dispomos. Assim, os dados na literatura ainda são poucos e não sabemos exatamente se há diferenças entre classes de animais e o significado das mesmas.

O mecanismo hemostático do sangue da serpente C.d. terrificus ocorre com a ativação de ambas as vias de coagulação (intrínseca e extrínseca), aparentemente com predomínio da ativação pela via extrínseca onde os inibidores plasmáticos em alta concentração não tem efeito importante. Por outro lado, a ativação do sistema intrínseco pode ser acelerada aumentando a ativação do sistema de contato e fator $\mathrm{V}$ pelos polifosfatos. Ainda, fica evidente a participação dos trombócitos no mecanismo hemostático e, embora não tenha sido comprovada a presença dos polifosfatos nos corpos densos dos trombócitos de C.d. terrificus, a sua existência e participação na hemostasia é muito provável. Assim, o mecanismo hemostático da C.d. terrificus é eficiente e bem adaptado, sendo evidente que há o equilíbrio entre ativação e inativação do sistema hemostático. Para uma compreensão mais detalhada desse sistema complexo, é fundamental realizar estudos para avaliar os outros fatores plasmáticos cuja dificuldade é aquisição de reagentes adequados. 
CONCLUSÕES 


\section{Conclusões}

O mecanismo hemostático da serpente $C . d$. terrificus, da mesma forma que nos humanos, apresenta a fase de iniciação, com participação importante da liberação do fator tissular e dos trombócitos. A presença de inibidores plasmáticos em alta concentração e quantidade menor de alguns fatores evidenciaram uma ativação da via intrínseca da coagulação mais lenta. Essa via pode ser acelerada na presença de polifosfatos que podem estar presentes nos corpos densos dos trombócitos. Portanto, juntamente com uma estrutura de fibrina diferente, a hemostasia dessa serpente é eficiente, com a possível vantagem de apresentar menor risco trombótico. 
RESUMO 


\section{Resumo}

A hemostasia previne a perda de sangue após uma lesão vascular e garante a fluidez sanguínea. Para isso há a participação de células carreadoras de fator tissular e também de plaquetas, além de fatores plasmáticos, cofatores, fosfolipídios e íons cálcio que resultam na liberação dos fibrinopeptídios do fibrinogênio e polimerização dos monômeros de fibrina, transformando-os em fibrina estável. Os polifosfatos também participam da ativação da via intrínseca da cascata de coagulação ativando o fator XII e a pré-calicreína plasmática. Os répteis possuem peculiaridades quanto ao mecanismo de coagulação, apresentando níveis altos de anticoagulantes circulantes e ausência ou deficiência de alguns fatores de coagulação. Pouco se sabe sobre a participação real dos trombócitos e polifosfatos no mecanismo hemostático de serpentes. Assim, o objetivo deste estudo foi investigar o mecanismo hemostático da serpente de C.d. terrificus, avaliando também o papel dos trombócitos e dos polifosfatos. Os testes de coagulação apresentaram tempos prolongados, mas o nível de fibrinogênio $(227,47 \pm 20,38 \mathrm{~g} / \mathrm{dL})$ foi semelhante ao humano. Foi constatada a presença de FXII, que foi ativado pelos polifosfatos, reduzindo o tempo de coagulação em Rotem. Os trombócitos de C.d. terrificus $\left(13,37 \pm 1,22 \times 10^{9} / \mathrm{L}\right)$ são células nucleadas elipsoidais, que apresentam superfície lisa quando não estão ativados. Esses trombócitos agregaram com colágeno $5,84 \pm 0,85 \Omega$ ) e ionóforo de cálcio $(24 \pm 3,3 \%)$. Porém, não ativaram com ADP, como previamente mostrado em outros répteis. A adesão trombocitária observada $(1,25 \pm 0,37$ $\%$ ) foi mais baixa do que em seres humanos (11\%), lembrando que a adaptação do método usado não foi totalmente adequada às serpentes. Embora se saiba pouco sobre a importância das variações das características morfológicas das fibras de fibrina, que em C.d. terrificus diferem das de ratos, humanos e outras espécies descritas de mamíferos, o tipo dessa rede de fibrina pode estar influenciando no processo final da hemostasia, juntamente com a participação dos trombócitos. A eficácia do mecanismo hemostático em serpentes $C . d$. terrificus parece estar relacionada principalmente à ativação da coagulação pelo fator tissular. Assim, a fase de iniciação é tão eficiente quanto em mamíferos, diferindo mais na fase de propagação do coágulo, ou seja, na via intrínseca. A baixa concentração de alguns fatores de coagulação e níveis elevados de inibidores naturais, tais como a antitrombina, interfere nesse sistema mais lento e possivelmente diminui os riscos trombóticos. 
ABSTRACT 


\section{Abstract}

Hemostasis prevents blood loss after vascular injury and provides the blood flow. Platelets and tissue factor bearing cell, plasma factors, cofactors, phospholipids and calcium ions participate in this process that results in the release of fibrinogen fibrinopeptides and polymerization of fibrin monomers, converting to stable fibrin. Polyphosphates also participate in the activation of the intrinsic pathway of the coagulation cascade by activating factor XII and plasma prekallikrein. The peculiarities of blood coagulation of reptiles are high levels of circulating anticoagulants and absence or low level of some coagulation factors. The role of thrombocytes and polyphosphates in the hemostatic mechanism of snakes is not well known. The objective of this study was to investigate the hemostatic mechanism of C.d. terrificus snake evaluating the role of thrombocytes and polyphosphates. Coagulation tests showed prolonged times, but the level of fibrinogen $(227.47 \pm 20.38 \mathrm{~g} / \mathrm{dL})$ was similar to human. It was also observed the presence of FXII activated by polyphosphates reducing the clotting time in Rotem. Thrombocytes of C.d. terrificus (13.37 $\left.\pm 1.22 \times 10^{9} / \mathrm{L}\right)$ are ellipsoidal nucleated cells, which exhibit smooth surface when not activated. These thrombocytes were activated by collagen $(5.84 \pm 0.85 \Omega)$ and calcium ionophore $(24 \pm 3.3 \%)$. However, they did not aggregate with ADP as previously shown in other reptiles. The thrombocytes adhesiveness observed $(1.25 \pm 0.37 \%)$ was lower than in humans $(11 \%)$, probably, in part because the adaptation of the method used was not fully adequate to snakes. Although little is known about the importance of morphological characteristics of C.d. terrificus fibrin fibers, which differ from rat, human and other mammalian species described, possibly this type of fibrin network may influence the final stages of hemostasis, with thrombocytes participation. The efficacy of the hemostatic mechanism in C.d. terrificus snakes seems to be mainly related to the activation of coagulation by tissue factor. Thus, the initiation phase is as efficient as in mammals, differing in the propagation phase of coagulation or intrinsic pathway. The low concentration of some coagulation factors and high levels of natural inhibitors such as antithrombin may be interfering with that system, and also preventing thrombotic diseases. 
APÊNDICES 


\section{Apêndice A - Abreviaturas}

ADP: difosfato de adenosina

AS: tamanho médio dos objetos corados

B.: Bothrops

C. d. terrificus: Crotalus durissus terrificus

$\mathrm{CaCl}_{2}$ : Cloreto de cálcio

CHCM: concentração de hemoglobina corpuscular média

$\mathrm{CoCl}_{2}$ : cloreto de cobalto

DAB: 3,3-diaminobenzidina

DAPI: 4',6-diamino-2- fenilindol

EACA: ácido epsílon aminocapróico

EDTA: ácido etilenodiamino tetra-acético

Fa: fator ativado

$g$ : unidade de aceleração

$\mathrm{H}_{2} \mathrm{O}_{2}$ : peróxido de hidrogênio

HCM: hemoglobina corpuscular média

HEPES: Ácido 2-[4-(2-hidroxietil)1-piperazinil]-etanosulfónico

$\mathrm{KCl}$ : cloreto de potássio

kDa: kilodalton

M: molar

$\mathrm{mA}$ : miliampère

$\mathrm{MgCl}_{2}$ : cloreto de magnésio

Min: minuto

$\mathrm{Na}_{2} \mathrm{CO}_{3}$ : carbonato de sódio

$\mathrm{NaCl}$ : cloreto de sódio; solução salina

$\mathrm{NaH}_{2} \mathrm{PO}_{4}$ : fostato de sódio monobásico

$\mathrm{NaOH}$ : hidróxido de sódio

Ob: número de objetos por foto

PAGE: eletroforese em gel de poliacrilamida

PolyP: polifosfatos

PBS: tampão fosfato salina

PMSF: fluoreto de fenil-metil-sulfonil 
Apêndices

PRT: plasma rico em trombócitos

ROTEM: Rotation Tromboelastogram analyser

s: segundo

SC: adesão da superfície coberta

SDS: dodecil sulfato de sódio

TAFI: inibidor de fibrinólise ativado pela trombina

TC: tempo de coagulação

TEMED: N, N, N', N' Tetrametiletilenodiamina

TFPI: inibidor do fator tissular plasmático

TP: tempo de protrombina

Tris: tris(hidroximetil)aminometano

TT: tempo de trombina

TTPA: tempo de tromboplastina parcial ativada

Tween 20: Monolaurato de Sorbitan polietilenoglicol

VCM: volume corpuscular médio 


\section{Apêndice B - Fatores da coagulação}

\begin{tabular}{|c|c|c|c|}
\hline Fator & Proteína & $\begin{array}{l}\text { Massa Molecular } \\
\qquad(\mathrm{kDa})\end{array}$ & $\begin{array}{c}\text { Concentração } \\
\text { Plasmática }(\mu \mathrm{g} / \mathrm{mL})\end{array}$ \\
\hline I & fibrinogênio & 340 & $2000-4000$ \\
\hline II & protrombina & 72 & 100 \\
\hline III & fator tissular & 37 & --- \\
\hline IV & íon cálcio & --- & --- \\
\hline $\mathrm{V}$ & proacelerina & 330 & 10 \\
\hline VII & proconvertina & 55 & 0,5 \\
\hline VIII & fator anti-hemofílico & 330 & 0,1 \\
\hline IX & fator Christmas & 55 & 5 \\
\hline$X$ & fator Stuart & 55 & 10 \\
\hline XI & $\begin{array}{l}\text { antecedente de } \\
\text { tromboplastina do plasma }\end{array}$ & 160 & 5 \\
\hline XII & fator Hageman & 80 & 30 \\
\hline XIII & $\begin{array}{l}\text { fator estabilizador da } \\
\text { fibrina }\end{array}$ & 320 & 10 \\
\hline--- & fator Von Willebrand & 220 & 10 \\
\hline--- & pré-calicreína & & 30 \\
\hline --- & $\begin{array}{l}\text { cininogênio de alto peso } \\
\text { molecular }\end{array}$ & & 80 \\
\hline
\end{tabular}

(Roberts e Lozier, 1992) 
REFERÊNCIAS BIBLIOGRÁFICAS 


\section{Referências Bibliográficas}

ALWOOD, A. J; DOWNEND, A. B.; BROOKS, M. B; SLENSKY, K.A.; FOX, J.A.; SIMPSON, S. A.; WADDELL, L. S.; BAUMGARDNER, J. E.; OTTO, C.M. Anticoagulant effects of low-molecular-weight heparins in healthy cats. Journal of Veterinary Internal Medicine, v. 21, n. 3, p. 378-387, May-Jun 2007.

AROCHA-PIÑANGO, C. L.; GORZULA, S. J.; OJEDA, A. The blood clotting mechanism of spectacled caiman Caiman crocodilus. Molecular Physiology, v. 2, p. 161-170, 1982.

BANFIELD, D. K.; MACGILLIVRAY, R. T. A. Partial characterization of vertebrate prothrombin cDNAs -amplification and sequence-analysis of the b-chain of thrombin from 9 different species. Proceedings of the National Academy of Sciences of the United States of America, v. 89, n. 7, p. 2779-2783, Apr 1992.

BAUER, N.; ERALP, O.; MORITZ, A. Establishment of reference intervals for kaolinactivated thromboelastography in dogs including an assessment of the effects of sex and anticoagulant use. Journal of Veterinary Diagnostic Investigation, v. 21, n. 5, p. 641648, Sep 2009.

BIGGS, C.; BAIN, B. J. Basic haematological techniques. In: BAIN, B. J.;BATES, I., et al (Ed.). Dacie and Lewis Practical Haematology. 11 th. Philadelphia: Elsevier Churchill Livingstone, 2011. cap. 3, p.23-56.

BIGGS, R. Techniques. In: BIGGS, R. (Ed.). Human blood coagulation, haemostasis and thrombosis. Oxford: Blackwell Scientific, 1972. cap. Appendix 2,

BROSOVIC, M. Investigation of haemostasis. Edinburgh: Churchill Livingstone, 1991. 267-278.

CAMPBELL, L. L. The thromboplastin activity of bovine thoracic aorta. Journal of the American Pharmaceutical Association-Scientific Edition, v. 43, n. 6, p. 359-360, 19541954.

CHUDZINSKI, A. M.; SEELAENDER, M. C. L.; KELEN, E. M. A. Standardization of anesthesia with pentobarbital in the snake Bothrops jararaca. Memórias do Instituto Butantan, v. 51, n. 4, p. 147-152, 1989.

COLLEN, D. The plasminogen (fibrinolytic) system. Thrombosis and Haemostasis, v. 82, n. 2, p. 259-70, Aug 1999. 
DACIE, J. V.; LEWIS, S. M. Reference ranges and normal values. In: (Ed.). Practical haematology. 7th. New York: Churchill Livingstone, 1991. cap. 2, p.9-17.

DAVIDSON, C. J.; TUDDENHAM, E. G.; MCVEY, J. H. 450 million years of hemostasis. Journal of Thrombosis and Haemostasis, v. 1, n. 7, p. 1487-1494, Jul 2003.

DAVIE, E. W.; RATNOFF, O. D. Waterfall sequence for intrinsic blood clotting. Science, v. 145, n. 363, p. 1310-\&, 1964.

DE MORAIS, K. B.; GREGO, K. F.; TANAKA-AZEVEDO, A. M. Identification of proteins similar to Bothrops jararaca coagulation inhibitor (BjI) in the plasmas of Bothrops alternatus, Bothrops jararacussu and Crotalus durissus terrificus snakes. Comparative Biochemistry and Physiology B-Biochemistry \& Molecular Biology, v. 149, n. 2, p. 236-240, Feb 2008.

DEAN, G. E.; FISHKES, H.; NELSON. P. J.; RUDNICK, G. The hydrogen ionpumping adenosine-triphosphatase of platelet dense granule membrane - differences from F1F0-type and phosphoenzyme-type ATPases. Journal of Biological Chemistry, v. 259, n. 15 , p. $9569-9574,1984$.

DENSON, K. W. E.; BIGGS, R. Tests of clotting function. In: (Ed.). Human blood, coagulation, haemostasis and thrombosis. Oxford: Blackwell Scientific Publications, 1972. cap. 12, p.288.

DOOLITTLE, R. F. Structural aspects of the fibrinogen to fibrin conversion. Advances in Protein Chemistry and Structural Biology, v. 27, p. 1-109, 1973.

The structure and evolution of vertebrate fibrinogen. Annals of the New York Academy of Sciences, v. 408, p. 13-27, Jun 271983.

1984.

Fibrinogen and fibrin. Annual Review of Biochemistry, v. 53, p. 195-229,

DOOLITTLE, R. F.; SURGENOR, D. M. Blood coagulation in fish. American Journal of Physiology, v. 203, n. 5, p. 964-\&, 1962.

ELIAS, A.; BONFILS, S.; DAOUD-ELIAS, M.; GAUTHIER, B.; SIÉ, P.; BOCCALON, H.; BONEU, B. Influence of long-term oral anticoagulants upon prothrombin fragment $1+2$, thrombin-antithrombin-III complex and d-dimer levels in patients affected by proximal deep-vein thrombosis. Thrombosis and Haemostasis, v. 69, n. 4, p. 302-305, Apr 11993. 
EPSTEIN, K. L.; BRAINARD, B.M.; LOPES, M. A.; BARTON, M. H.; MOORE, J.N. Thrombelastography in 26 healthy horses with and without activation by recombinant human tissue factor. Journal of Veterinary Emergency and Critical Care, v. 19, n. 1, p. 96-101, Feb 2009.

ESCOLAR, G.; KRUMWIEDE, M.; WHITE, J. G. Organization of the actin cytoskeleton of resting and activated platelets in suspension. American Journal of Pathology, v. 123, n. 1, p. 86-94, Apr 1986.

ESMON, C. T. Regulatory mechanisms in hemostasis: natural anticoagulants. In: HOFFMAN, R.;BENZ JR, E. J., et al (Ed.). Hematology Basic Principles and Practice. 4th. Philadelphia: Elsevier Churchill Livingstone, 2005. cap. 111, p.19611973.

FONG, D. L.; HA, J. C.; HOTCHKISS, C. E. Thromboelastography Values from Pigtail Macaques (Macaca nemestrina): Effects of Age and Sex. Journal of the American Association for Laboratory Animal Science, v. 51, n. 1, p. 94-100, Jan 2012.

FRANCO, F. L. Origem e diversidade das serpentes. In: CARDOSO, J. L. C.;FRANÇA, F. O. S., et al (Ed.). Animais peçonhentos no Brasil. 1st. São Paulo: Sarvier, 2003. cap. 3, p.13-32.

FROST, C. L.; NAUDÉ, R. J.; OELOFSEN, W.; JACOBSON, B. Comparative blood coagulation studies in the ostrich. Immunopharmacology, v. 45, n. 1-3, p. 75-81, Dec 1999.

FUKAMI, M. H.; DANGELMAIER, C. A.; BAUER, J. S.; HOLMSEN, H. Secretion, subcellular-localization and metabolic status of inorganic pyrophosphate in humanplatelets - a major constituent of the amine-storing granules. Biochemical Journal, v. 192, n. 1, p. 99-105, 1980.

FUNASA. Manual de diagnóstico e tratamento de acidentes por animais peçonhentos. Brasília: 112 p. 2001.

GENTRY, P. A. Comparative aspects of blood coagulation. Veterinary Journal, v. 168, n. 3, p. 238-51, Nov 2004.

GREGO, K. F.; ALVES, J. A. S.; RAMEH DE ALBUQUERQUE, L. C.; FERNANDES, W. Hematological references for wild recently-caught white-tailed lancehead (Bothrops leucurus). Arquivo Brasileiro De Medicina Veterinaria E Zootecnia, v. 58, n. 6, p. 1240-1243, Dec 2006. 
HACKETT, E.; HANN, C. Slow clotting of reptile bloods. Journal of Comparative Pathology, v. 77, n. 2, p. 175-80, Apr 1967.

HARLOW, E.; LANE, D. Antibodies: A Laboratory Manual. In: (Ed.). New York: Cold Spring Harbor, 1988. p.471-510.

HILLER, E. Basic Principles of Hemostasis. In: MUNKER, R. H., E.GLASS, J.PAQUETTE, R. (Ed.). Modern Hematology. 2nd: Humana Press, 2007. cap. 19, p.327-345.

HOFFMAN, M. Remodeling the blood coagulation cascade. Journal of Thrombosis and Thrombolysis, v. 16, n. 1-2, p. 17-20, Aug-Oct 2003.

HOFFMAN, M.; MONROE, D. M. A cell-based model of hemostasis. Thrombosis and Haemostasis, v. 85, n. 6, p. 958-965, Jun 2001.

IWANAGA, S. Primitive coagulation systems and their message to modern biology. Thrombosis and Haemostasis, v. 70, n. 1, p. 48-55, Jul 1993.

JAGADEESWARAN, P.; SHEEHAN, J. P. Analysis of blood coagulation in the zebrafish. Blood Cells Molecules and Diseases, v. 25, n. 15, p. 239-249, Aug 151999.

JANKUN, J.; SELMAN S. H.; KECK， R. W.; ŁYSIAK-SZYDŁOWSKA, W.; SKRZYPCZAK-JANKUN, E. Very long half-life plasminogen activator inhibitor type 1 reduces bleeding in a mouse model. BJU International, v. 105, n. 10, p. 14691476, May 2010.

KASPEREIT, F.; DOERR, B.; DICKNEITE, G. The effect of fibrinogen concentrate administration on coagulation abnormalities in a rat sepsis model. Blood Coagulation \& Fibrinolysis, v. 15, n. 1, p. 39-43, Jan 2004.

KRAUS, F.; MINK, D. G.; BROWN, W. M. Crotaline intergeneric relationships based on mitochondrial DNA sequence data. Copeia, n. 4, p. 763-773, Dec 271996.

KUBALEK, S.; MISCHKE, R.; FEHR, M. Investigations on blood coagulation in the green iguana (Iguana iguana). Journal of Veterinary Medicine A: Physiology, Pathology and Clinical Medicine, v. 49, n. 4, p. 210-6, May 2002.

KULAEV, I. S.; VEGABOV, V. M. Polyphosphate metabolism in micro-organisms. Advances in microbial physiology, v. 24, 1983. 
LAEMMLI, U. K. Cleavage of structural proteins during the assembly of the head of bacteriophage T4. Nature, v. 227, n. 259, p. 680-5, Aug 151970.

LAFFAN, M.; MANNING, R. Investigation of haemostasis. In: BAIN, B. J.;BATES, I., et al (Ed.). Dacie and Lewis Practical Haematology. 11 th. Philadelphia: Elsevier Churchill Livingstone, 2011. cap. 18, p. 393-445.

LANG, T.; BAUTERS, A.; BRAUN, S. L.; PÖTZSCH, B.; VON PAPE, K. W.; KOLDE, H. J.; LAKNER, M. Multi-centre investigation on reference ranges for ROTEM thromboelastometry. Blood Coagulation \& Fibrinolysis, v. 16, n. 4, p. 301310, Jun 2005.

LEVI, M.; TEN CATE, H.; VAN DER POLL, T. Endothelium: Interface between coagulation and inflammation. Critical Care Medicine, v. 30, n. 5, p. S220-S224, May 2002.

LEVIN, J. The evolution of mammalian platelets. In: MICHELSON, A. D. (Ed.). Platelets. 2nd. Massachusetts, USA: Academic Press - Elsevier, 2007. cap. 1, p.3-22.

LORENZ, B.; LEUCK, J.; KÖHL, D.; MULLER, W. E.; SCHRÖDER, H. C. AntiHIV-1 activity of inorganic polyphosphates. Journal of Acquired Immune Deficiency Syndromes and Human Retrovirology, v. 14, n. 2, p. 110-118, Feb 1997.

MACFARLANE, R. G. Enzyme cascade in blood clotting mechanism and its function as biochemical amplifier. Nature, v. 202, n. 493, p. 498-\&, 19641964.

MEDVED, L.; WEISEL, J. W. Recommendations for nomenclature on fibrinogen and fibrin. Journal of Thrombosis and Haemostasis, v. 7, n. 2, p. 355-9, Feb 2009.

MELGAREJO, A. R. Serpentes peçonhentas do Brasil. In: CARDOSO, J. L. C.;FRANÇA, F. O. S., et al (Ed.). Animais peçonhentos no Brasil. 1st. São Paulo: Sarvier-FAPESP, 2003. cap. 4, p.33-61.

MONROE, D. M.; HOFFMAN, M. What does it take to make the perfect clot? Arteriosclerosis Thrombosis and Vascular Biology, v. 26, n. 1, p. 41-48, Jan 2006.

MONROE, D. M.; HOFFMAN, M.; ROBERTS, H. R. Transmission of a procoagulant signal from tissue factor bearing cells to platelets. Blood Coagulation \& Fibrinolysis, v. 7, n. 4, p. 459-464, Jun 1996.

MOREY, T. E.; MODELL, J. H.; GARCIA, J. E.; BEWERNITZ, M.; DERENDORF, H.; VARSHNEY, M.; GRAVENSTEIN， N.; SHAH， D. O.; DENNIS， D. M. Thromboelastographic and Pharmacokinetic Profiles of Micro- and Macro emulsions of 
Propofol in Swine. Biopharmaceutics \& Drug Disposition, v. 31, n. 5-6, p. 269-277, Jul-Sep 2010.

MORRISSEY, J. H. Plasma factor VIIa: Measurement and potential clinical significance. Haemostasis, v. 26, p. 66-71, Jan 1996.

MORRISSEY, J. H.; MUTCH, N. J. Tissue structure and function. In: COLMAN, R. W.;CLOWES, A. W., et al (Ed.). Hemostasis and thrombosis: basic principles and clinical practice. Philadelphia: Lippincott Williams and Wilkins, 2006. cap. 5, p.91106.

MOTTA, R. O.; CUNHA, L. M.; LEITE, R. C.; DA SILVA, I.J.; PINTO, A.C.; BRAGA, E. M.; DA CUNHA, A. P.; DE OLIVEIRA, P. R. Hepatozoon spp. (Apicomplexa: Hepatozoidae) infection and selected hematological values of the neotropical rattlesnake, Crotalus durissus collilineatus (Linnaeus, 1758) Serpentes: Viperidae), from Brazil. Journal of Zoo and Wildlife Medicine, v. 42, n. 3, p. 399407, Sep 2011.

MÜLLER， F.; MUTCH， N. J.; SCHENK， W. A.; SMITH， S. A.; ESTERL, L.; SPRONK, H. M.; SCHMIDBAUER， S.; GAHL， W. A.; MORRISSEY， J. H.; RENNÉ, T. Platelet Polyphosphates Are Proinflammatory and Procoagulant Mediators In Vivo. Cell, v. 139, n. 6, p. 1143-1156, Dec 2009.

MULLER, F.; RENNE, T. Novel roles for factor XII-driven plasma contact activation system. Current Opinion in Hematology, v. 15, n. 5, p. 516-521, Sep 2008.

MUTCH, N. J.; MYLES, T.; LEUNG, L. L.; MORRISSEY, J. H. Polyphosphate binds with high affinity to exosite II of thrombin. Journal of Thrombosis and Haemostasis, v. 8, n. 3, p. 548-555, Mar 2010.

NAHAS, L.; BETTI, F.; KAMIGUTI, A. S.; SATO, H. Blood coagulation inhibitor in a snake plasma (Bothrops jararaca). Thrombosis et Diathesis Haemorrhagica, v. 30, n. 1, p. 106-13, Sep 151973.

NAHAS, L.; KAMIGUTI, A. S.; BETTI, F.; SANO-MARTINS, I. S.; RODRIGUES, M. I. Blood coagulation mechanism in the snakes Waglerophis merremii and Bothrops jararaca. Comparative Biochemistry and Physiology a-Physiology, v. 69, n. 4, p. 739-743, 1981.

NATT, M. P.; HERRICK, C. A. A new blood diluent for counting the eryrthrocytes and leucocytes of the chicken. Poultry Science, v. 31, p. 735-738, 1951. 
NIELSEN, V. G.; GEARY, B. T.; BAIRD, M. S. Evaluation of the contribution of platelets to clot strength by thromboelastography in rabbits: The role of tissue factor and cytochalasin D. Anesthesia and Analgesia, v. 91, n. 1, p. 35-39, Jul 2000.

PELLIZZON, C. H.; AZEVEDO, A.; CASALETTI, L.; LUNARDI, L. O. The thrombocyte aggregation process in the turtle Phrynopys hilarii (Chelonia). An ultrastructural study. Journal of submicroscopy citology and pathology, v. 34, p. 323327, 2002.

PERAZZOLO, L. M.; LORENZINI, D. M.; DAFFRE, S.; BARRACCO, M. A. Purification and partial characterization of the plasma clotting protein from the pink shrimp Farfantepenaeus paulensis. Comp Biochem Physiol B Biochem Mol Biol, v. 142, n. 3, p. 302-7, Nov 2005.

PRETORIUS, E.; BRIEDENHANN, S.; MARX, J.; FRANZ, R. C. Structural changes in the fibrin network of a Pretoria family with dysfibrinogenemia: A scanning electron microscopical study. Ultrastructural Pathology, v. 30, n. 3, p. 167-176, May-Jun 2006.

PRETORIUS, E.A; VIEIRA, W. A.; OBERHOLZER, H. M.; AUER, R. E. J.;PRETORIUS, R. Comparative Scanning Electron Microscopy of Platelets and Fibrin Networks of Human and Differents Animals. International Journal of Morphology, v. 27, n. 1, p. 69-76, Mar 2009.

PREZOTO, B. C.; HIRAICHI, E.; ABDALLA, F. M. F.; PICARELLI, Z. P. Activation of the kallikrein kinin system in plasma of some Brazilian snakes. Comparative Biochemistry and Physiology C-Pharmacology Toxicology \& Endocrinology, v. 99, n. 1-2, p. 135-139, 1991.

RATNOFF, O. D.; MENZIE, C. A new method for determination of fibrinogen in small samples of plasma. The journal of laboratory and clinical medicine, v. 37, n. 2, p. 316-320, 1951.

RATNOFF, O. D.; ROSENBERG, M. J.; EVERSON, B.; EMANUELSON, M.; TULODZIECKI, N. Notes on clotting in a burmese python (Python molurus bivittatus). Journal of Laboratory and Clinical Medicine, v. 115, n. 5, p. 629-635, May 1990.

ROBERTS, H. R.; LOZIER, J. N. New perspectives on the coagulation cascade. Hospital Practice, v. 27, n. 1, p. 97-105, 109-12, Jan 151992.

ROSENFELD, G. Retração do coágulo sanguíneo. Revista clínica de São Paulo, v. 10, 1941. 
RUIZ, F. A.; LEA, C. R.; OLDFIELD, E.; DOCAMPO, R. Human platelet dense granules contain polyphosphate and are similar to acidocalcisomes of bacteria and unicellular eukaryotes. Journal of Biological Chemistry, v. 279, n. 43, p. 4425044257, Oct 2004.

SAGRIPANTI, A.; CARPI, A. Antithrombotic and prothrombotic activities of the vascular endothelium. Biomedicine \& Pharmacotherapy, v. 54, n. 2, p. 107-111, Mar 2000.

SALAKIJ， C.; SALAKIJ， J.; APIBAL， S.; NARKKONG， N. A.; CHANHOME, L.; ROCHANAPAT, N. Hematology, morphology, cytochemical staining, and ultrastructural characteristics of blood cells in king cobras (Ophiophagus hannah). Veterinary Clinical Pathology, v. 31, n. 3, p. 116-126, 2002.

SANTOS, K. R.; TAKAHIRA, R. K.; RALL, V. L. M.; CALDERÓNI, C.; SEQUEIRA, J. L.; SILVA, R. J. Pulmonary, microbiological and hematological changes in Crotalus durissus terrificus (Serpentes, Viperidae) parasitized by nematodes of the genus Rhabdias (Nematoda, Rhabdiasidae). Arquivo Brasileiro De Medicina Veterinaria E Zootecnia, v. 60, n. 3, p. 667-674, Jun 2008.

SCHOUTEN, M.; WIERSINGA, W. J.; LEVI, M.; VAN DER POLL, T. Inflammation, endothelium, and coagulation in sepsis. Journal of Leukocyte Biology, v. 83, n. 3, p. 536-545, Mar 2008.

SINAN. Acidente por animais peçonhentos - notificações registradas no sistema de informação de agravos de notificação. SINAN net. Disponível em http://dtr2004.saude.gov.br/sinanweb/tabnet/dh?sinannet/animaisp/bases/animaisbrnet.d ef, 2014. Acesso em: 01 de Julho.

SMITH, S. A. The cell-based model of coagulation. Journal of Veterinary Emergency and Critical Care, v. 19, n. 1, p. 3-10, Feb 2009.

SMITH，S. A.; CHOI，S. H.; DAVIS-HARRISON， R.; HUYCK，J.; BOETTCHER, J.; RIENSTRA, C. M.; MORRISSEY, J. H. Polyphosphate exerts differential effects on blood clotting, depending on polymer size. Blood, v. 116, n. 20, p. 4353-4359, Nov 2010.

SMITH, S. A.; MORRISSEY, J. H. Polyphosphate enhances fibrin clot structure. Blood, v. 112, n. 7, p. 2810-2816, Oct 2008. 
SMITH, S. A.; MUTCH, N. J.; BASKAR, D.; ROHLOFF, P.; DOCAMPO, R.; MORRISSEY, J. H. Polyphosphate modulates blood coagulation and fibrinolysis. Proceedings of the National Academy of Sciences of the United States of America, v. 103, n. 4, p. 903-908, Jan 2006.

SOSLAU， G.; WALLACE， B.; VICENTE， C.; GOLDENBERG， S. J.; TUPIS, T.; SPOTILA， J.; GEORGE， R.; PALADINO， F.; WHITAKER， B.; VIOLETTA, G.; PIEDRA, R. Comparison of functional aspects of the coagulation cascade in human and sea turtle plasmas. Comparative Biochemistry and Physiology B-Biochemistry \& Molecular Biology, v. 138, n. 4, p. 399-406, Aug 2004.

STILLER, R. A.; BELAMARICH, F. A.; SHEPRO, D. Aggregation and release in thrombocytes of the duck. The american journal of physiology, v. 229, p. 206-210, 1975.

TANAKA-AZEVEDO, A. M.; TANAKA, A. S.; SANO-MARTINS, I. S. A new blood coagulation inhibitor from the snake Bothrops jararaca plasma: isolation and characterization. Biochemical and Biophysical Research Communications, v. 308, n. 4, p. 706-12, Sep 52003.

TANIZAKI, M. M.; KAWASAKI, H.; SUZUKI, K.; MANDELBAUM, F. R. Purification of a proteinase-inhibitor from the plasma of Bothrops jararaca (jararaca). Toxicon, v. 29, n. 6, p. 673-681, 1991.

TENNENT, G. A.; BRENNAN, S. O.; STANGOU, A. J.; O'GRADY, J.; HAWKINS, P. N.; PEPYS, M. B. Human plasma fibrinogen is synthesized in the liver. Blood, v. 109, n. 5, p. 1971-4, Mar 12007.

THOMSON, J. M. A practical guide to blood coagulation and haemostasis. 1st. London: Longman, 1970. 220.

VARON, D.; SAVION, N. Impact Cone anf Plate(let) Analyser. In: MICHELSON, A. D. (Ed.). Platelets. 2. Canada: Academic Press, 2007. cap. 29, p.535-544.

VIEIRA, C. O.; TANAKA, A. S.; SANO-MARTINS, I. S.; MORAIS, K. B.; SANTORO, M. L.; TANAKA-AZEVEDO A. M. Bothrops jararaca fibrinogen and its resistance to hydrolysis evoked by snake venoms. Comparative Biochemistry and Physiology B-Biochemistry \& Molecular Biology, v. 151, n. 4, p. 428-432, Dec 2008.

WEI, A. H.; SCHOENWAELDER, S. M.; ANDREWS, R. K.; JACKSON, S. P. New insights into the haemostatic function of platelets. British Journal of Haematology, v. 147, n. 4, p. 415-430, Nov 2009. 
WEISEL, J. W. Fibrinogen and fibrin. Advances in protein chemistry, v. 70, p. 24799, 2005.

WEISEL, J. W.; LITVINOV, R. I. Mechanisms of fibrin polymerization and clinical implications. Blood, v. 121, n. 10, p. 1712-1719, Mar 72013.

WENCEL-DRAKE, J. D.; PAINTER, R. G.; ZIMMERMAN, T. S.; GINSBERG, M. H. Ultrastructural localization of human platelet thrombospondin, fibrinogen, fibronectin, and vonWillebrand factor in frozen thin section. Blood, v. 65, n. 4, p. 929-938, 1985 1985.

WHITE, J. G. Dense bodies of human platelets - inherent electron opacity of serotonin storage particles. Blood-the Journal of Hematology, v. 33, n. 4, p. 598-\&, 1969.

Platelet Structure. In: MICHELSON, A. D. (Ed.). Platelets. 2nd. Philadelphia: Academic Press, 2011. cap. 3, p.45-73.

WOJTASZEK, J. S. Hematology of the grass snake Natrix natrix natrix . Comparative Biochemistry and Physiology a-Physiology, v. 100, n. 4, p. 805-812, 1991.

WOOD, H. G.; CLARK, J. E. Biological aspects of inorganic polyphosphates. Annual Review of Biochemistry, v. 57, p. 235-260, 19881988.

WÜSTER, W.; FERGUSON, J. E.; QUIJADA-MASCAREÑAS, J. A.; POOK, C. E.; SALOMÃO, M. D. A. G.; THORPE, R. S. Tracing an invasion: landbridges, refugia, and the phylogeography of the Neotropical rattlesnake (Serpentes : Viperidae : Crotalus durissus). Molecular Ecology, v. 14, n. 4, p. 1095-1108, Apr 2005.

XU, X.; DOOLITTLE, R. F. Presence of a vertebrate fibrinogen-like sequence in an echinoderm. Proc Natl Acad Sci U S A, v. 87, n. 6, p. 2097-101, Mar 1990. >.

ZUG, G. R.; VITT, L. J.; CALDWELL, J. P. Herpetology: an introductory biology of amphibians and reptiles. San Diego: Academic Press, 2001. 630. 